\title{
Tuning Dynamically Formed Active Phases and Catalytic Mechanisms of in Situ Electrochemically-Activated Layered Double Hydroxide for Oxygen Evolution Reaction
}

Soressa Abera Chala, ${ }^{\mathrm{a}, \mathrm{c}}$ Meng-Che Tsai, ${ }^{* b, \mathrm{c}}$ Bizualem Wakuma Olbasa, ${ }^{\mathrm{a}, \mathrm{c}}$ Keseven Lakshmanan, ${ }^{\mathrm{b}, \mathrm{c}}$ Wei-Hsiang Huang, ${ }^{b, c, e}$ Wei-Nien Su, ${ }^{\text {bb,c }}$ Yen-Fa Liao, ${ }^{\text {e }}$ Jyh-Fu Lee, ${ }^{\text {e }}$ Hongjie Dai, ${ }^{d}$ Bing Joe Hwang*a,b,c,e

${ }^{a}$ NanoElectrochemistry Laboratory, Department of Chemical Engineering, National Taiwan University of Science and Technology, Taipei 106, Taiwan.

bNanoElectrochemistry Laboratory, Graduate Institute of Applied Science and Technology,

National Taiwan University of Science and Technology, Taipei 10607, Taiwan

'Sustainable Energy Development Center, National Taiwan University of Science and

Technology, Taipei 106, Taiwan

${ }^{\mathrm{d}}$ Department of Chemistry, Stanford University, Stanford, California 94305, United States

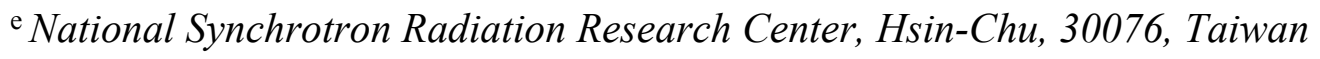

"Corresponding Authors: E-mail: bjh@mail.ntust.edu.tw (BJ Hwang); wsu@mail.ntust.edu.tw (WN Su); and mctsai@mail.ntust.edu.tw (MC Tsai) 


\section{Experimental Section}

Turnover Frequency (TOF). TOF was calculated according to the following equation.

$\mathrm{TOF}=\frac{J \cdot A}{4 \cdot F \cdot n}$

where $J$ is the measured current density at an overpotential of $300 \mathrm{mV}$, A is the surface area of the electrode, number 4 represents four-electron transfer for per mole of $\mathrm{O}_{2}, \mathrm{~F}$ is the Faraday constant, and $\mathrm{n}$ is the number of moles of the $\mathrm{Ni}$ atom loaded on the electrode.

The in situ Raman Measurements. The Raman measurements were implemented in a confocal UniRAM micro-Raman spectroscopy integrated by Protrustech Co., Ltd using thermoelectrically cooled charge-coupled (CCD) working at $-60^{\circ} \mathrm{C}$ and $50 \mathrm{x}$ objective in a backscattering geometry with the excitation source of laser wavelength of $633 \mathrm{~nm}$. The electrochemical-Raman measurements were performed with a potentiostat (PGSTAT302N, Metrohm Autolab), using a homemade three-electrode system $\mathrm{Ag} / \mathrm{AgCl}$ (sat. $\mathrm{KCl}$, sat. $\mathrm{AgCl}$ ), platinum, and modified glassy carbon electrode (GCE) were used as a reference, counter electrode, and working electrode, respectively. The electrochemical-Raman measurements were made in the aqueous solution of 0.1 $\mathrm{M} \mathrm{KOH}$ electrolyte before and after the guest anions (13 $\mathrm{mM}$ chloride and bromide) were introduced into the electrolyte. The measurements were executed chronoamperometrically. All potentials for these measurements are reported versus the reversible hydrogen electrode (RHE).

In situ X-ray Absorption Spectroscopy. X-ray absorption spectra (XAS) were recorded at the beamline BL12B1 of the Super Photon ring-8 GeV (Spring-8) and 17C1 of the National Synchrotron Radiation Research Centre (NSRRC) of Taiwan, following a procedure described in detail elsewhere. ${ }^{1}$ The X-ray beam energy was regulated by a monochromator operating in fixed-exit mode using a Si (111) 
crystal pair. The in situ X-ray absorption spectra, including X-ray Absorption Near Edge Fine Structure (XANES) and Extended X-ray Absorption Fine Structure (EXAFS), were collected for the Ni K-edge and Mn K-edge using transmission mode. The in situ measurement was performed in $0.1 \mathrm{M} \mathrm{KOH}$ at the various applied potential within a potential range of oxygen evolution reaction (OER) at room temperature with $\left(13 \mathrm{mM}\right.$ of $\left.\mathrm{Br}^{-}\right)$and without the guest anion. The spectra were collected after applying a potential for at least 20 minutes to ensure that the system had reached a steady-state in each condition. Prior to XAS measurement, the NiMn-LDH/carbon paper (CP) electrodes were prepared by dropping catalyst ink. In general, the amounts of $\mathrm{Ni}$ and $\mathrm{Mn}$ on the $\mathrm{CP}$ electrode were controlled to reach the edge jump of $\mathrm{Ni}$ around $1 \sim 1.5$ and ensured enough amount for $\mathrm{Mn}$ in the transmission mode measurement. A schematic of the in situ setup is shown in Figure S1. The control of parameters for EXAFS measurements, data collection modes, and calculation of errors were all done as per the guidelines set by the International XAFS Society Standards and Criteria Committee. Standard procedures were followed to analyze the XAS data. First, the raw absorption spectrum in the pre-edge region was fitted to a straight line, while the background above the edge was fitted with a cubic spline. The EXAFS function, $\chi$, was obtained by subtracting the post-edge background from the overall absorption and then normalized with respect to the edge jump step. The normalized $\chi(\mathrm{E})$ was transformed from energy space to $k$-space, where $k$ is the photoelectron wave vector. The $\chi(k)$ data were multiplied by $k^{2}$ or $k^{3}$ to compensate for the damping of EXAFS oscillations in the high $k$-region. Subsequently, $k^{2}$ - or $k^{3}$-weighted $\chi(\mathrm{k})$ data in the k-space ranging from 3.6 to $11.4 \AA^{-1}$ for Ni K-edge and from 3.1 to $10.3 \AA^{-1}$ for Mn Kedge were Fourier transformed (FT) to $r$-space to separate the EXAFS contributions from the different coordination shells. A nonlinear least-squares algorithm was applied to the curve fitting of the EXAFS in the $r$-space between 0.8 and $3.2 \AA$ for Ni K-edge. Due to the possible presence 
of two structure phases at the applied potential, the models of $\mathrm{Ni}(\mathrm{OH})_{2}$ and $\mathrm{NiOOH}$ are used to perform EXAFS fitting for some conditions. All of the computer programs were implemented in the Athena 0.8.056 package with the backscattering amplitude and the phase shift for the specific atom pairs being theoretically calculated by using Ifeffit 1.2.11 code. From these analyses, structural parameters, such as coordination number $(\mathrm{N})$, bond distance $(\mathrm{R})$, the Debye-Waller factor $\left(\Delta \sigma^{2}\right)$, and the inner potential shift $\left(\Delta E_{0}\right)$, were calculated.

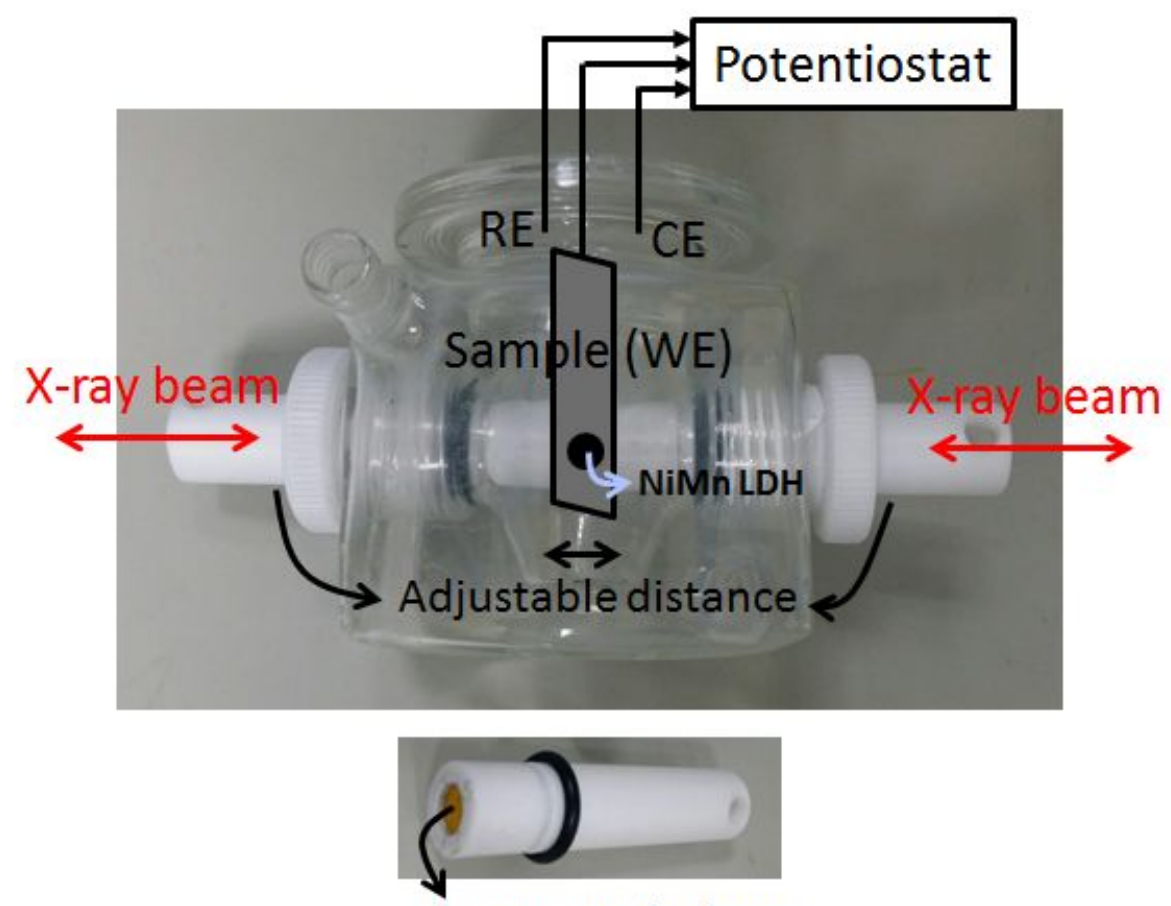

Kapton window

Figure S1. A photograph of in situ XAS setup for transmission mode. One side of the Teflon tubes is sealed by Kapton tapes to avoid leakage of the electrolyte during the test. The space nearby working electrode is adjustable by two Teflon tubes to ensure enough contact between electrode and electrolyte under applied potential. During spectra collection, the distance can be decreased to lower than $1 \mathrm{~mm}$ to minimize the effect of liquid to X-ray penetration. WE, RE, and CE stand for working, reference, and counter electrodes. 
Operando X-ray diffraction. The in situ XRD measurements were performed at the beamline of $01 \mathrm{C} 1$ of the NSRRC, Hsinchu, Taiwan, equipped with a gold target X-ray radiation $(\lambda=0.83 \AA)$. The $2 \theta$ scan was implemented in the range of 5-100 degrees and then converted to $\mathrm{Cu} K \alpha_{1}(1.5418$ A) to simplify the comparison with the reported literature and in-house XRD results. The electron storage ring was operated at $15 \mathrm{keV}$ with a beam current of $360 \mathrm{~mA}$. The in situ XRD patterns were collected using a homemade in situ cell upon potentiostatic cycling electrolyte $(0.1 \mathrm{M} \mathrm{KOH})$ before and after the guest anion $(13 \mathrm{mM})$ introduced into the electrolyte. The diffraction patterns of each sample were collected at time intervals of $10 \mathrm{~min}$ for various applied potentials.

\section{Computational details}

All DFT calculations in the present work were performed by the Vienna $A b$ initio Simulation Package (VASP) 5.4.4 code $^{2}$ with the Perdew-Burke-Ernzerhof (PBE) functional. ${ }^{3}$ The ionelectron interaction was described by the projector augmented wave (PAW) method ${ }^{4}$ with a kinetic energy cutoff of $600 \mathrm{eV}$. A $2 \times 2 \times 2$ supercell of the $\mathrm{Ni}(\mathrm{OH})_{2}$ structure was employed to simulate the NiMn layered double hydroxide (NiMn-LDHs) with Ni/Mn atomic ratio of 3. A MonkhorstPack $k$-point mesh with a size of $5 \times 5 \times 3$ was applied for the calculations. Considering the magnetic nature of Ni-based hydroxides, the spin polarization was employed for all calculations. In addition, the DFT-D3 correction method in Grimme's scheme ${ }^{5,6}$ was also used to accurately describe the long-range vdW interactions. For structural optimization, the atomic positions were allowed to relax in all three directions, while the shape and volume of the supercell were also relaxed until the total energy and force were less than $10^{-5} \mathrm{eV}$ per atom and $0.05 \mathrm{eV} \AA^{-1}$, respectively. 
In order to be consistent with the experimentally prepared material, carbonate group $\left(\mathrm{CO}_{3}\right)$ as a host anion was located upon Mn sites of the NiMn-LDHs to reach charge compensation. The bulk model of NiMn-LDHs with host anion $\mathrm{CO}_{3}{ }^{2-}$ is shown in Figure S16a. Due to the charge state of $2^{-}$for the carbonate group, the total charge should be compensated by two LDHs (two $\mathrm{Mn}^{3+}$ ) and one $\mathrm{CO}_{3}$ group. Here the $d$-spacing along (001) direction of LDH layers was examined for $\mathrm{CO} 3$ or $\mathrm{Br}$ as the host anion and the cases with/without guest anion $(\mathrm{Br})$, all the relaxed structures can be observed in Figure S16a-c. In addition, we also examine the ionic exchange between $\mathrm{CO}_{3}$ and $\mathrm{Br}$ as the host anions. According to the calculation of the formation energy of reaction R1, thermodynamic feasibility for the ionic exchange between $\mathrm{CO} 3$ (Model A) and $\mathrm{Br}$ (Model B) in the LDH can be determined.

$$
\mathrm{NiMn}-\mathrm{LDH}-\mathrm{CO}_{3}^{2-}+2 \mathrm{NaBr} \rightarrow \mathrm{NiMn}-\mathrm{LDH}-2 \mathrm{Br}^{-}+\mathrm{Na}_{2} \mathrm{CO}_{3}
$$

Furthermore, the intercalation energy for the host/guest anion $\mathrm{Br}$ can be calculated to understand the effect of bromide, the energy calculation using the following equation (S2).

Considering $\mathrm{Br}^{-}$as a host anion:

$$
\Delta E_{\text {int }}=E_{\mathrm{LDH}(2 \mathrm{Br})}+E_{\mathrm{Na}_{2} \mathrm{CO}_{3}}-\left(E_{\mathrm{LDH}\left(\mathrm{CO}_{3}\right)}+2 E_{\mathrm{NaBr}}\right)
$$

Considering $\mathrm{Br}^{-}$as a guest anion:

$$
\Delta E_{\text {int }}=E_{\mathrm{LDH}\left(\mathrm{CO}_{3}\right)+\mathrm{Br}}-\left(E_{\mathrm{LDH}\left(\mathrm{CO}_{3}\right)}+\frac{1}{2} E_{B r_{2}}\right)
$$

Where $E_{\mathrm{LDH}\left(\mathrm{CO}_{3}\right)}$ is the total energy of NiMn-LDHs (Model A), $E_{\mathrm{LDH}(2 \mathrm{Br})}$ is the total energy of NiMn-LDHs (Model B), $E_{\mathrm{LDH}\left(\mathrm{CO}_{3}\right)+\mathrm{Br}}$ is the total energy of Br-intercalated NiMn-LDHs (Model C), $E_{\mathrm{Na}_{2} \mathrm{CO}_{3}}$ is the total energy of $\mathrm{Na}_{2} \mathrm{CO}_{3}$ molecule, $E_{\mathrm{NaBr}}$ is the total energy of $\mathrm{NaBr}$ molecule and $E_{B r_{2}}$ is the total energy of $\mathrm{Br}_{2}$ molecule. 


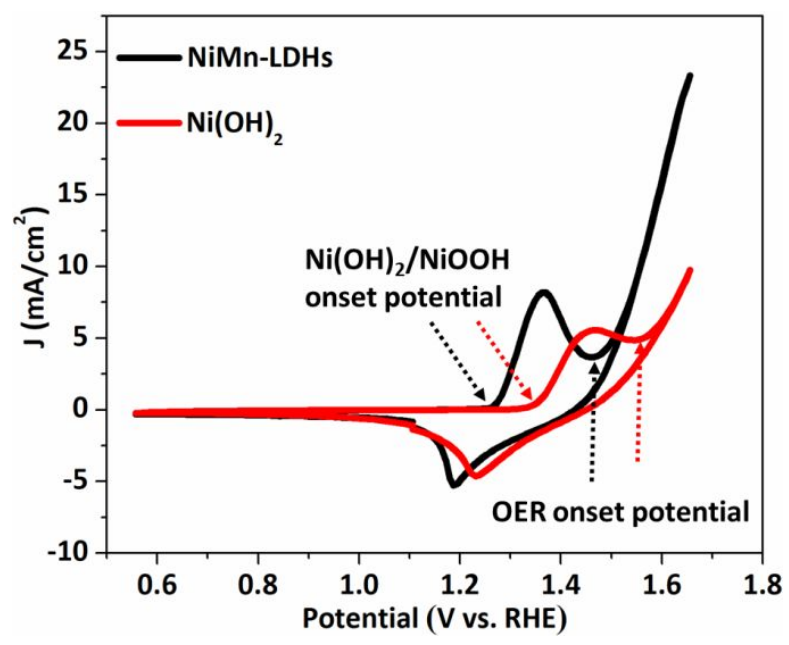

Figure S2. Cyclic voltammetry (CV) of NiMn-LDHs (black) and $\beta-\mathrm{Ni}(\mathrm{OH})_{2}$ (red) in $1 \mathrm{M} \mathrm{KOH}$ at $50 \mathrm{mV} / \mathrm{s}$ sweep rate.

It can be seen that the onset potential of $\mathrm{Ni}(\mathrm{OH})_{2} / \mathrm{NiOOH}$ redox transition for LDHs slightly shifts to lower overpotential upon the introduction of guest anions, suggesting that the in situ intercalation of the guest anions offers higher site activity thereby boosted the OER activity. As more guest anions (1-7 mM) are introduced, the redox couple of $\mathrm{Ni}(\mathrm{OH})_{2} / \mathrm{NiOOH}$ for $\mathrm{NiMn}-\mathrm{LDHs}$ shifts to lower overpotentials, and the peak area of the redox couple increases (Figure S3 and Figure S4).

Unlike the bromide guest anions, the peak area of the redox transition of $\mathrm{Ni}(\mathrm{OH})_{2} / \mathrm{NiOOH}$ and its normalized current density is not significant as the concentration of $\mathrm{Cl}^{-}$increased, as shown in Figure S4. In addition, the OER limiting current density of $\beta-\mathrm{Ni}(\mathrm{OH})_{2}$ considerably decreased as the concentration of guest anions increased, demonstrating that the Ni sites were embedded with the anions finally led to descent site populations and accumulation structure of the material, which seriously affect the final OER activity. The inset of Figure S3 and Figure S4 shows the redox 
transition of $\mathrm{Ni}(\mathrm{OH})_{2} / \mathrm{NiOOH}$ species preceding the oxygen evolution, which is commonly found in Ni-based OER catalysts. ${ }^{7-9}$
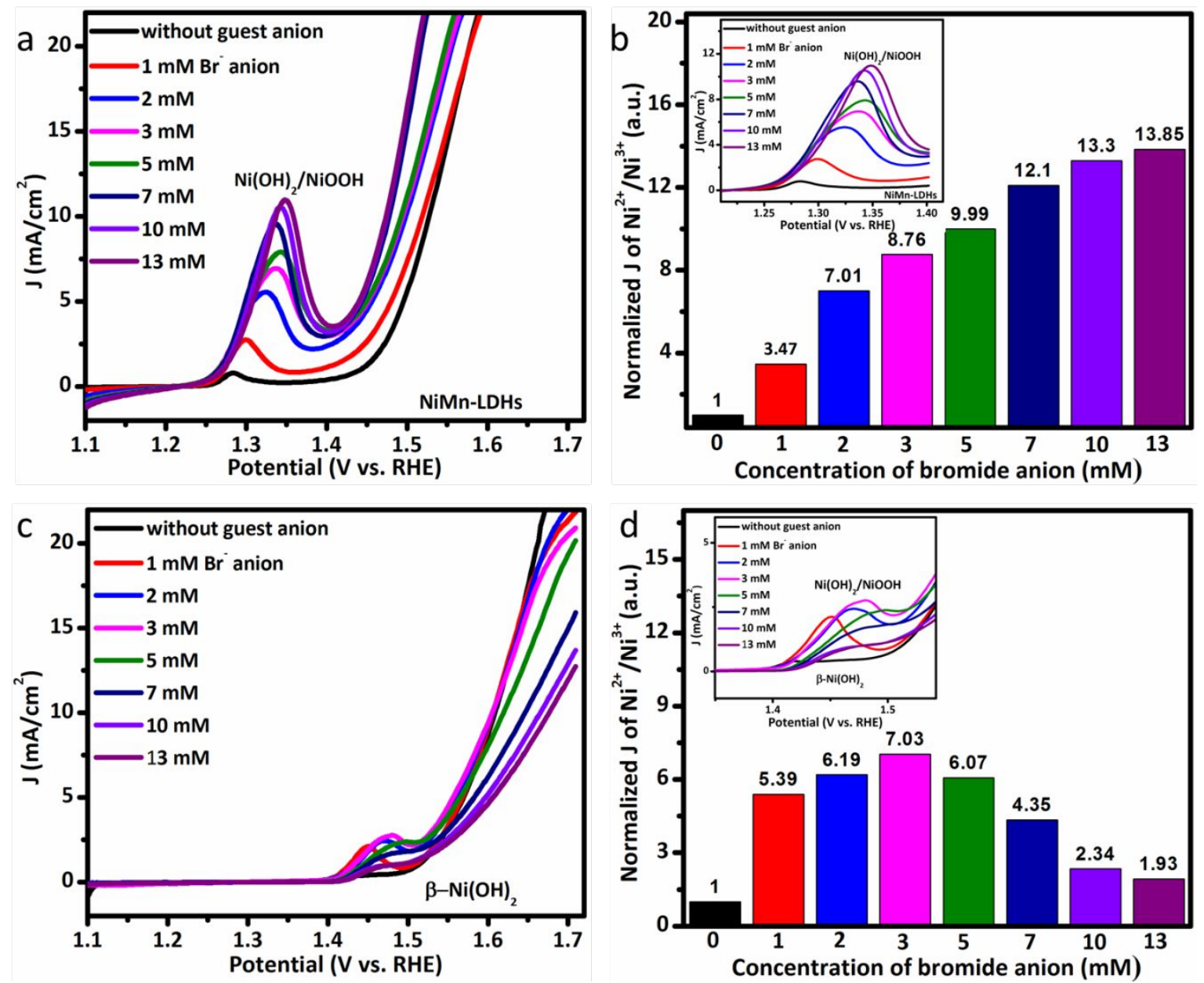

Figure S3. (a) OER LSV curves of NiMn-LDHs in the absence and presence of bromide (1-13 $\mathrm{mM}$ ) guest anions in Ar-saturated $1 \mathrm{M} \mathrm{KOH}$ at $1 \mathrm{mV} / \mathrm{s}$ sweep rate and rotation rate of $1600 \mathrm{rpm}$.

(b) The normalized current density of the anodic $\mathrm{Ni}(\mathrm{OH})_{2} / \mathrm{NiOOH}$ redox transitions of NiMnLDHs at different concentration of bromide guest anions with respect to the current density obtained without the guest anions. (c) OER LSV curves of $\beta-\mathrm{Ni}(\mathrm{OH})_{2}$ without and with bromide (1-13 mM) guest anions in Ar-saturated $1 \mathrm{M} \mathrm{KOH}$ at $1 \mathrm{mV} / \mathrm{s}$ sweep rate and rotation rate of 1600 rpm. (d) The normalized current density of the anodic $\mathrm{Ni}(\mathrm{OH})_{2} / \mathrm{NiOOH}$ redox transitions of $\beta$ - 
$\mathrm{Ni}(\mathrm{OH})_{2}$. The inset is enlarged scale of redox transition of $\mathrm{Ni}(\mathrm{OH})_{2} / \mathrm{NiOOH}$ for $\mathrm{NiMn}-\mathrm{LDH}$ and $\beta-\mathrm{Ni}(\mathrm{OH})_{2}$ electrodes.
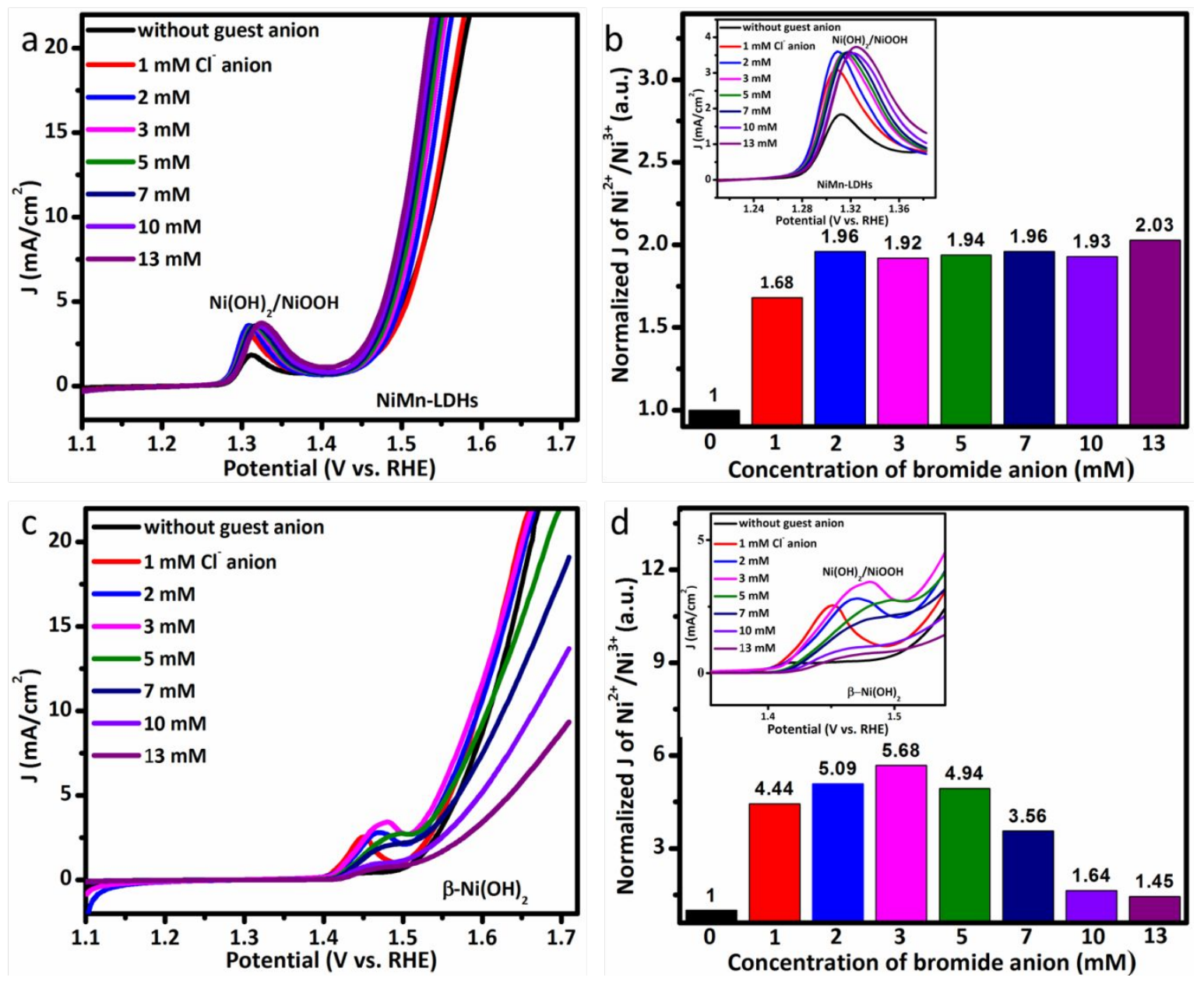

Figure S4. (a) OER LSV curves of NiMn-LDHs in the absence and presence of chloride (1-13 $\mathrm{mM}$ ) guest anions in Ar-saturated $1 \mathrm{M} \mathrm{KOH}$ at $1 \mathrm{mV} / \mathrm{s}$ sweep rate and rotation rate of $1600 \mathrm{rpm}$.

(b) The normalized current density of the anodic $\mathrm{Ni}(\mathrm{OH})_{2} / \mathrm{NiOOH}$ redox transitions of NiMnLDHs at different concentrations of chloride guest anions with respect to the current density obtained without the guest anions. (c) OER LSV curves of $\beta-\mathrm{Ni}(\mathrm{OH})_{2}$ in the absence and presence of chloride (1-13 mM) guest anions in Ar-saturated $1 \mathrm{M} \mathrm{KOH}$ at $1 \mathrm{mV} / \mathrm{s}$ sweep rate and rotation rate of $1600 \mathrm{rpm}$. (d) The normalized current density of the anodic $\mathrm{Ni}(\mathrm{OH})_{2} / \mathrm{NiOOH}$ redox 
transitions of $\beta-\mathrm{Ni}(\mathrm{OH})_{2}$. The inset is an enlarged scale of redox transition of $\mathrm{Ni}(\mathrm{OH})_{2} / \mathrm{NiOOH}$ for NiMn-LDHs and $\beta-\mathrm{Ni}(\mathrm{OH})_{2}$ electrodes.

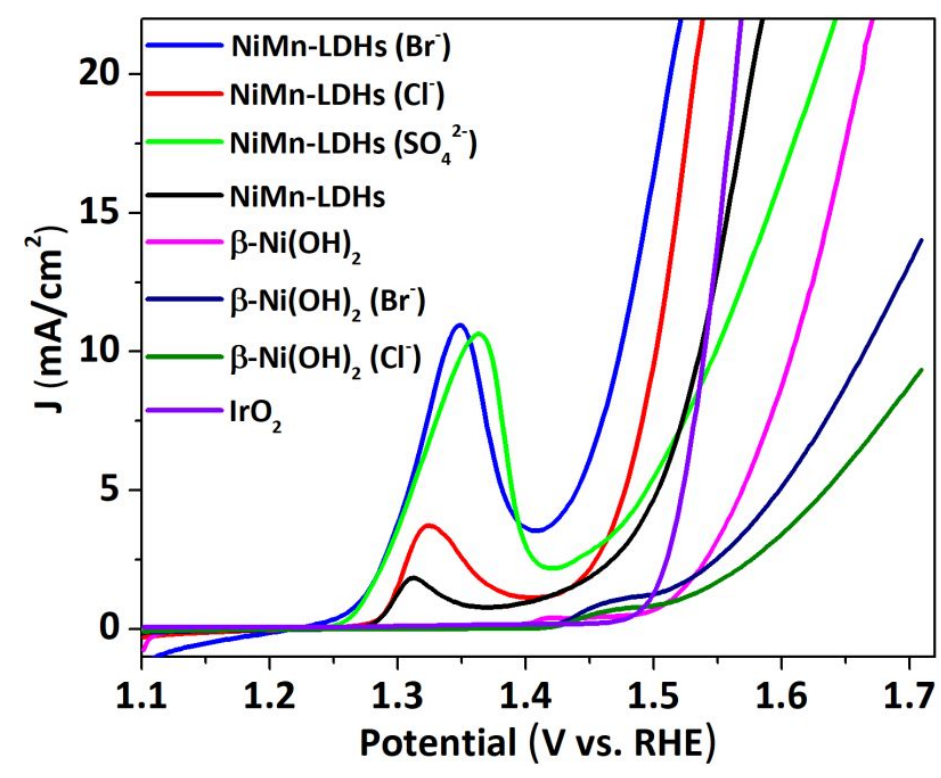

Figure S5. LSV curves of OER activity for NiMn-LDHs and $\beta-\mathrm{N}-(\mathrm{OH})_{2}$ catalysts with and without guest anions evaluated in $1 \mathrm{M} \mathrm{KOH}$ at rotating speed of $1600 \mathrm{rpm}$ along with the commercial $\mathrm{IrO}_{2}$. 


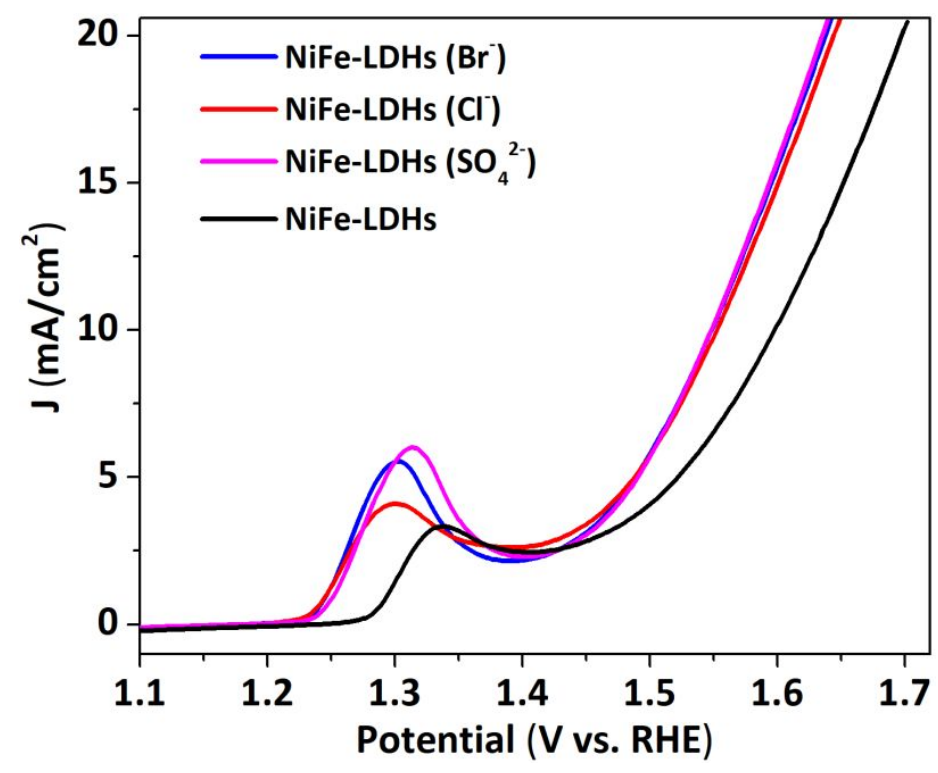

Figure S6. OER LSV curves of NiFe-LDHs with and without the guest anions in Ar-saturated 1 $\mathrm{M} \mathrm{KOH}$ electrolytes with a scan rate of $1 \mathrm{mV} \mathrm{s}^{-1}$ and rotating speed of $1600 \mathrm{rpm}$.

The electrochemical active surface area (ECSA) is a crucial parameter to evaluate the relative performance. ${ }^{10}$ To estimate the ECSA of NiMn-LDHs with and without the guest anions, CV tests are performed in a potential window of the non-faradaic region $(0.90-1.20 \mathrm{~V} v s$. RHE) at different scan rates $\left(10-50 \mathrm{mV} \mathrm{s}^{-1}\right)$ in $1 \mathrm{M} \mathrm{KOH}$ electrolyte. Next, the differences in current density variation $\left(\Delta J=J_{a}-J_{c}\right)$ at $1.05 \mathrm{~V} v s$. RHE are to be plotted against the scan rates. The plotted lines can be fitted by linear regression enabling the estimation of double-layer capacitance $\left(\mathrm{C}_{\mathrm{dl}}\right)$, where the slope is twice of $\mathrm{C}_{\mathrm{dl}}$. The large $\mathrm{C}_{\mathrm{dl}}$ manifests more exposed surface site populations. ${ }^{11}$ 

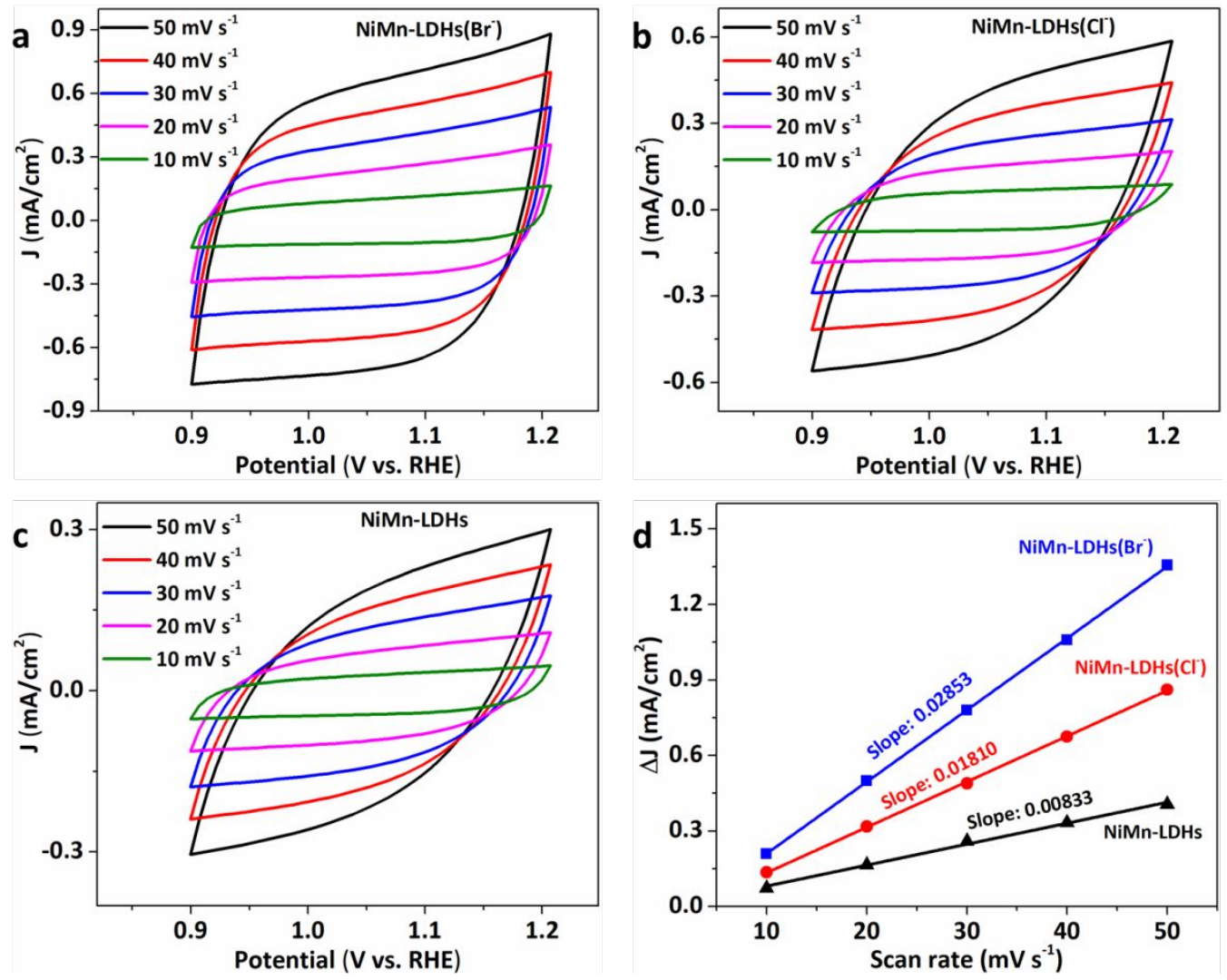

Figure S7. Cyclic voltammetry curves of (a) NiMn-LDHs (Br-) (b) NiMn-LDHs $\left(\mathrm{Cl}^{-}\right)$and (c) pristine NiMn-LDHs electrodes in $1 \mathrm{M} \mathrm{KOH}$ with different scan rates; (d) $\Delta J=\left(J_{a}-J_{c}\right)$ of NiMnLDHs (Br), NiMn-LDHs $\left(\mathrm{Cl}^{-}\right)$, and pristine NiMn-LDHs plotted against scan rates. The slopes equivalent to twice the double layer capacitance $\left(2 \mathrm{C}_{\mathrm{dl}}\right)$ were used to represent electrochemical active surface area (ECSA). The unit of slopes $\left(2 \mathrm{C}_{\mathrm{dl}}\right)$ is $\mathrm{mF} \mathrm{cm}-2$. 


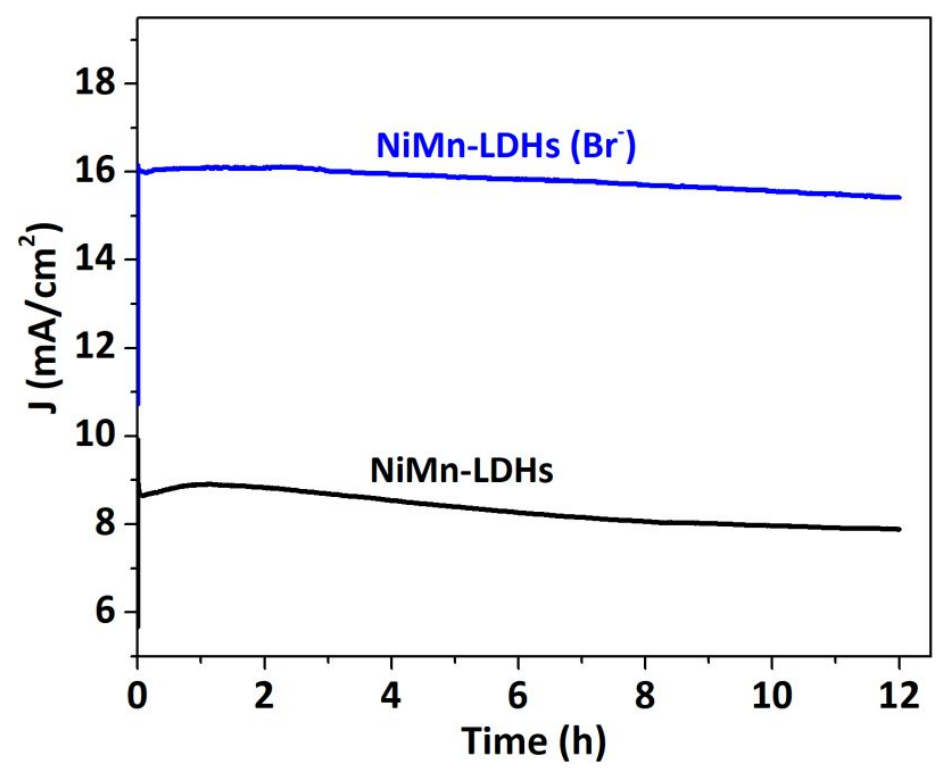

Figure S8. Chronoamperometric measurements of pristine NiMn-LDHs and NiMn-LDHs with Brguest at an overpotential of $270 \mathrm{mV}$ for $12 \mathrm{~h}$ in $1 \mathrm{M} \mathrm{KOH}$ electrolyte.

The gaseous products from the OER catalyzed by NiMn-LDHs with and without guest anions and commercial $\mathrm{IrO}_{2}$ catalysts were analyzed using gas chromatography (GC). A constant overpotential of $270 \mathrm{mV}$ was maintained for $3 \mathrm{~h}$ during gas chromatography measurement. Faradaic efficiency is estimated from the total amount of charge Q(C) passed through the cell and the total amount of produced oxygen $\mathrm{n}_{\mathrm{O} 2}(\mathrm{~mol})$. Assuming that four electrons are needed to produce one $\mathrm{O}_{2}$ molecule, the Faradaic efficiency can be calculated as follows:

Faradaic efficiency $=\left(4 \times \mathrm{n}_{\mathrm{O} 2} \times \mathrm{F}\right) / \mathrm{Q}$

where $\mathrm{F}$ is the Faraday constant $(96485 \mathrm{C} / \mathrm{mol})$. 

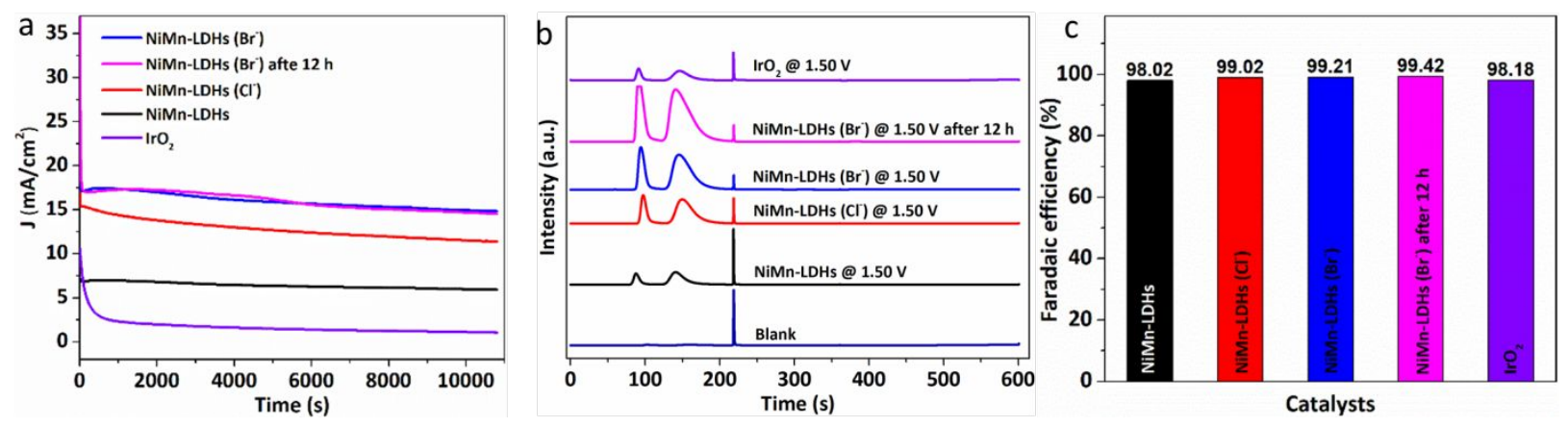

Figure S9. (a) Chronoamperometry curves of NiMn-LDHs with and without the guest anions and commercial $\mathrm{IrO}_{2}$ catalysts at an overptential of $270 \mathrm{mV}$ in Ar-saturated $1 \mathrm{M} \mathrm{KOH}$ electrolyte during GC measurement. (b) GC curves (c) Faradaic efficiency of OER catalyzed by NiMn-LDHs with and without the guest anions and commercial $\mathrm{IrO}_{2}$ electrodes at an overpotential of $270 \mathrm{mV} . \mathrm{O}_{2}$ peak position were assigned by standard gas reference.

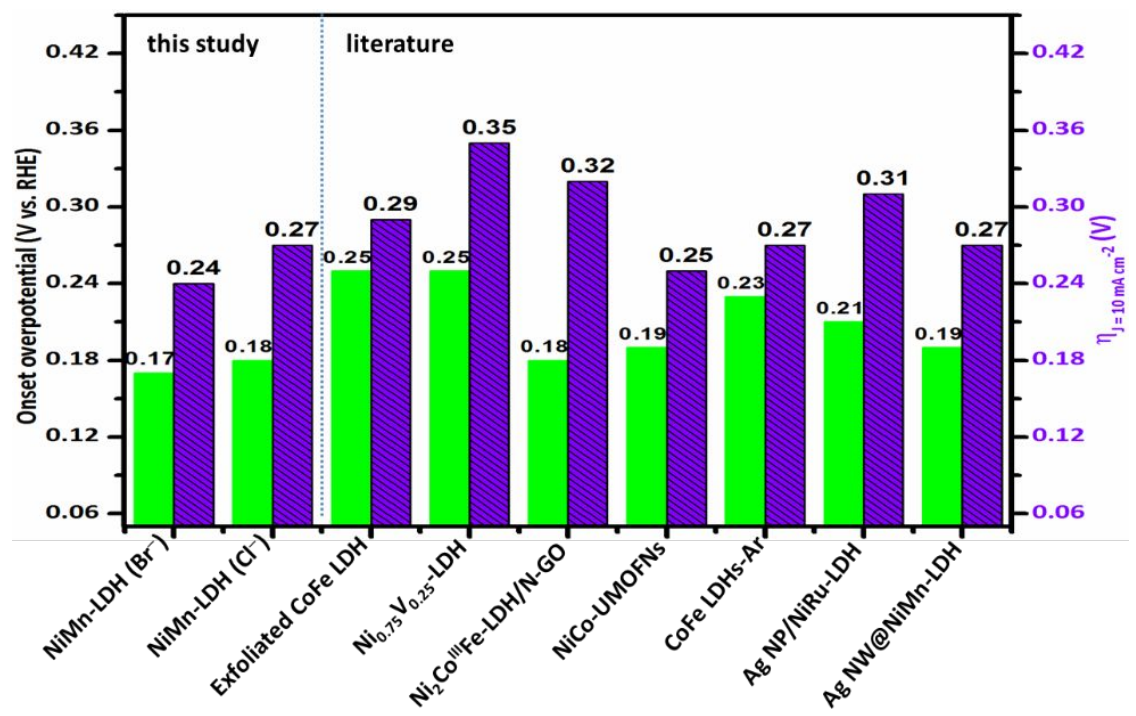

Figure S10. The OER onset overpotential and overpotentials required to deliver a current density of $10 \mathrm{~mA} / \mathrm{cm}^{2}$ for NiMn-LDH (with guest anions) catalysts of this study (left side) in comparison to the published literature (right side). Detailed activity values are given in Table S1. 
Table S1. Comparison of the catalytic activity of in situ intercalated guest anions of NiMn-LDHs with the recently reported best electrocatalysts.

\begin{tabular}{|c|c|c|c|c|c|}
\hline Electrocatalysts & $\begin{array}{l}\text { Onset } \\
\text { potential (V) }\end{array}$ & $\begin{array}{c}\mathrm{E}_{\text {OER }}(\mathrm{V}) \\
\left(10 \mathrm{mAcm}^{-2}\right)\end{array}$ & $\begin{array}{c}\text { OER Tafel } \\
\text { slope } \\
\left.(\mathrm{mV} \mathrm{dec})^{-1}\right)\end{array}$ & $\begin{array}{c}\text { Electrolyte } \\
\mathrm{KOH} \\
{[\mathrm{M}]}\end{array}$ & Reference \\
\hline NiMn-LDHs (Br-) & 1.40 & 1.47 & 29 & 1 & This study \\
\hline NiMn-LDHs (Cl-) & 1.41 & 1.50 & 37 & 1 & This study \\
\hline Ag NW@NiMn-LDHs & 1.42 & 1.50 & 40.2 & 1 & 11 \\
\hline $\mathrm{Au} / \mathrm{NiFe}-\mathrm{LDHs}$ & - & 1.47 & 36 & 1 & 12 \\
\hline Ag NP/NiRu-LDHs & 1.44 & 1.54 & 33 & 0.1 & 7 \\
\hline $\mathrm{Ni}_{2} \mathrm{Co}^{\mathrm{III}} \mathrm{Fe}-\mathrm{LDH} / \mathrm{N}-\mathrm{GO}$ & 1.41 & 1.55 & 56.8 & 0.1 & 13 \\
\hline NiCo-UMOFNs & 1.42 & 1.48 & 42 & 1 & 14 \\
\hline $\mathrm{Ni}_{0.75} \mathrm{~V}_{0.25}$-LDHs & 1.48 & 1.58 & 50 & 1 & 10 \\
\hline CoFe LDHs-Ar & 1.46 & 1.50 & 37.85 & 1 & 15 \\
\hline $\begin{array}{l}\mathrm{H}_{2} \mathrm{O} \text {-plasma exfoliated } \\
\mathrm{CoFe} \text { LDHs }\end{array}$ & 1.48 & 1.52 & 27.8 & 1 & 16 \\
\hline NiFe-LDH/CNT & 1.45 & $\begin{array}{l}1.48 @ \\
5 \mathrm{mAcm}^{-2}\end{array}$ & 31 & 1 & 8 \\
\hline 3D NiFe-LDH-POM & - & 1.43 & 67 & 0.1 & 17 \\
\hline
\end{tabular}

As shown in Figure S11a-b, the introduction of guest anions into the electrolyte accomplished with the anion interaction, and this interaction allows in situ intercalation of the guest anions between the interlayer spaces of LDHs. The in situ intercalation of guest anions interrupts the hydrogen bonds and ionic bonds in the interlayers of LDHs, disturbing the normal charge balance and increases the interlayer spaces of LDH which leads to delamination of the positively charged host layers from each other. Thus, the in situ intercalation of the guest anions in the layers of LDHs can increase the interlayer spaces of the nanosheets which in turn affects the intrinsic properties of 
the site activity and site populations thereby leads to high OER activity. Moreover, the introduction of guest anions can tune the electronic properties and structure of LDH nanosheets which in turn influences the intrinsic properties of the active sites. The intensity and peak positions of characteristic diffraction peaks for $\beta-\mathrm{Ni}(\mathrm{OH})_{2}$ remains unchanged during the OER process (Figure S11c-d). The diffraction peaks at $21^{\circ}$ are attributed to the carbon paper substrate.
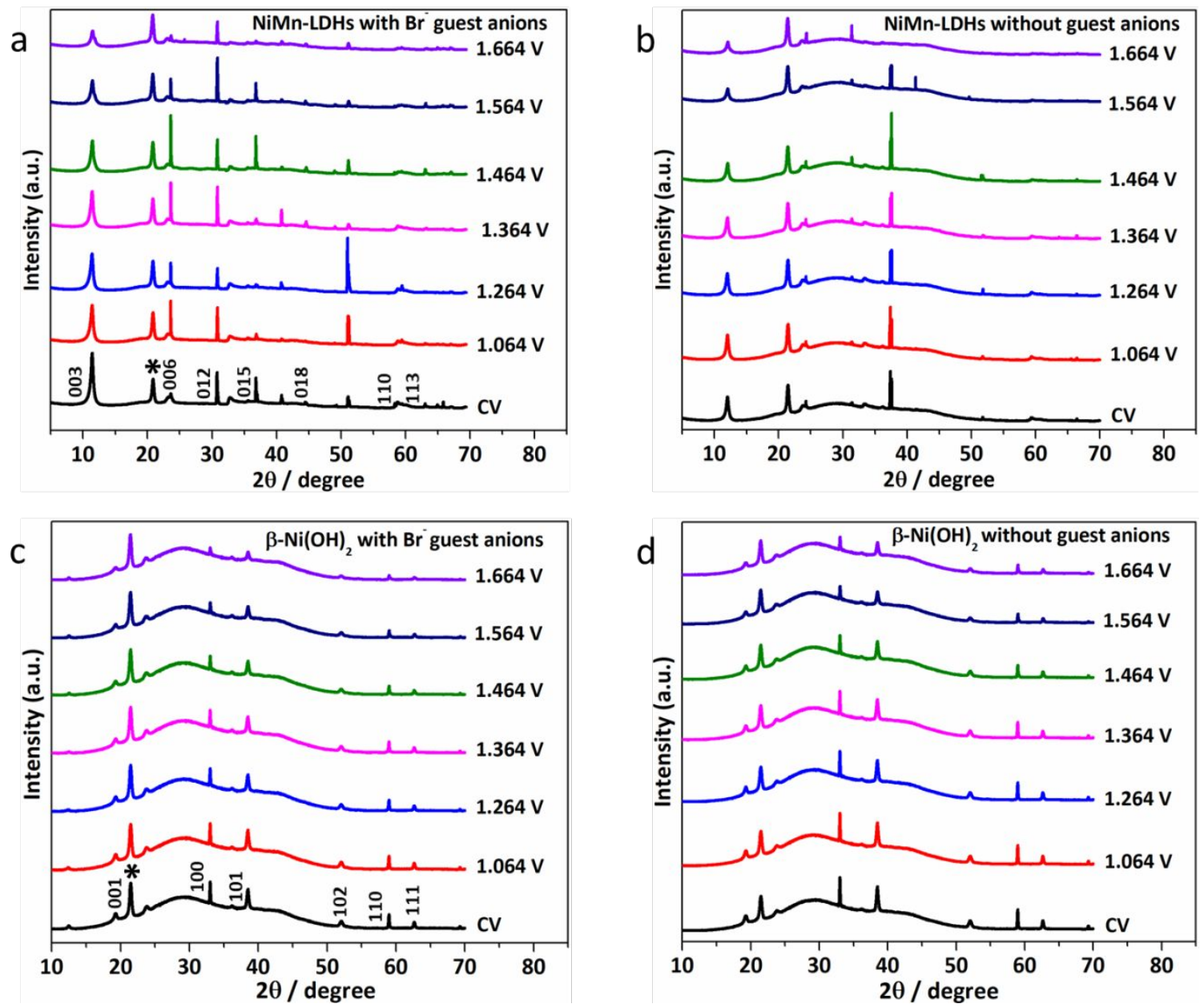

Figure S11. (a, b) In situ XRD patterns of NiMn-LDHs with and without $\mathrm{Br}^{-}$guest anions during the OER process. (c, d) In situ XRD patterns of $\mathrm{Ni}(\mathrm{OH})_{2}$ with and without guest anions during the OER process obtained at different potential chronoamperometrically. 
It can be seen that the intensity of diffraction peak of 003 diffraction plane significantly decreases with increasing electrode voltage. The electrochemical result already confirmed that there is a reversible redox transition of $\mathrm{Ni}(\mathrm{OH})_{2} / \mathrm{NiOOH}$ during the whole process of OER. However, there is no new peak detected due to the short lifetime of intermediate species ( $\mathrm{NiOOH})$ on the timescale of the XRD scans going on and thus keeps the diffraction peaks without any change.

Table S2. Basal spacing estimated from 003 and 006 diffraction patterns for the in situ XRD obtained during the OER process for NiMn-LDHs with and without $\mathrm{Br}^{-}$guest anions.

\begin{tabular}{|c|c|c|c|c|c|c|c|c|}
\hline & & \multicolumn{3}{|c|}{ LDHs without anion } & \multicolumn{4}{|c|}{ LDHs with guest anion } \\
\hline Potential & & 003 & & 006 & & 003 & & 006 \\
\hline$(\mathrm{V} v s$. & $2 \theta$ & d-spacing & $2 \theta$ & d-spacing & $2 \theta$ & d-spacing & $2 \theta$ & d-spacing \\
\hline RHE) & & $(\AA)$ & & $(\AA)$ & & $(\AA)$ & & $(\AA)$ \\
\hline $\mathrm{CV}$ & 12.043 & 7.340 & 24.242 & 3.666 & 11.443 & 7.724 & 23.600 & 3.765 \\
\hline 1.064 & 12.043 & 7.340 & 24.243 & 3.666 & 11.421 & 7.739 & 23.607 & 3.764 \\
\hline 1.264 & 12.021 & 7.353 & 24.250 & 3.665 & 11.422 & 7.738 & 23.615 & 3.763 \\
\hline 1.364 & 12.043 & 7.340 & 24.257 & 3.664 & 11.421 & 7.739 & 23.622 & 3.762 \\
\hline 1.464 & 12.085 & 7.314 & 24.257 & 3.664 & 11.471 & 7.705 & 23.615 & 3.763 \\
\hline 1.564 & 12.085 & 7.314 & 24.279 & 3.661 & 11.471 & 7.705 & 23.615 & 3.763 \\
\hline 1.646 & 12.113 & 7.297 & 24.343 & 3.652 & 11.471 & 7.705 & 23.643 & 3.759 \\
\hline
\end{tabular}



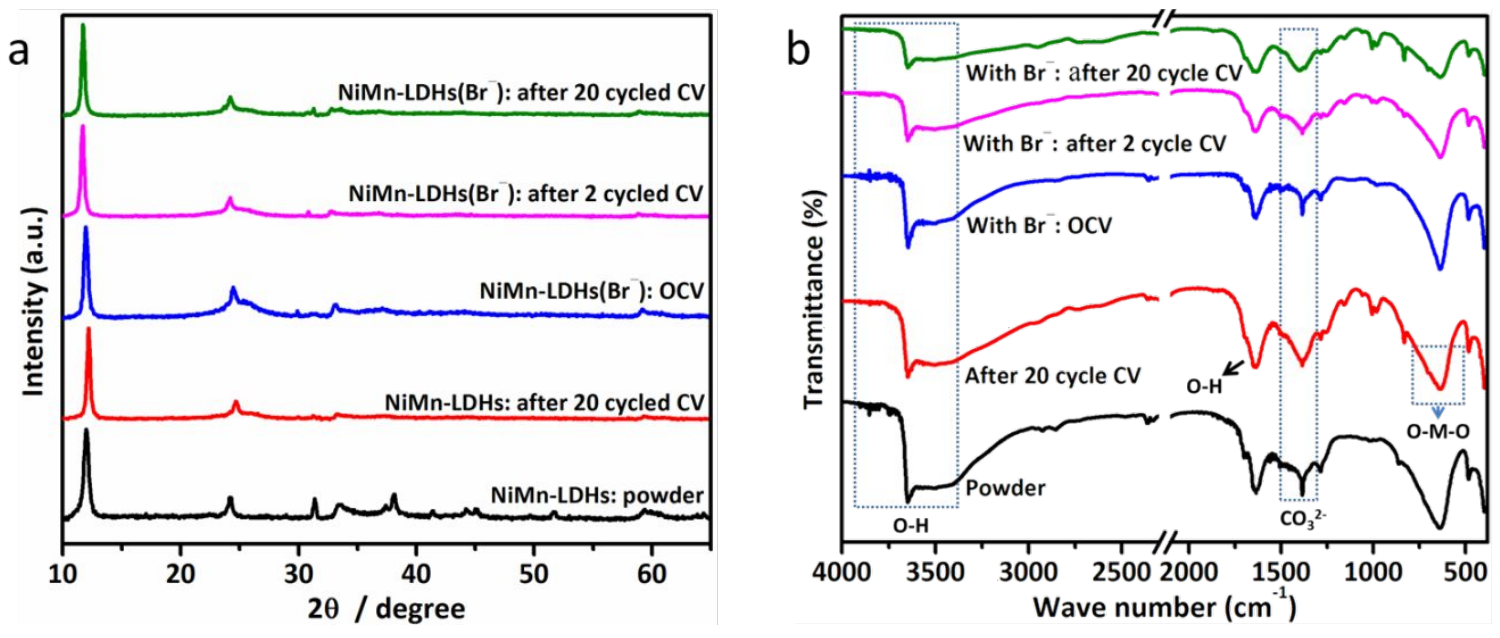

Figure S12. (a) XRD patterns and (b) FT-IR spectra of NiMn-LDHs before and after CV measurements with and without the guest anions.

Table S3. Basal spacing estimated from 003 and 006 diffraction patterns for the ex situ in-house XRD obtained before and after $\mathrm{CV}$ measurement for NiMn-LDHs with and without $\mathrm{Br}^{-}$guest anions.

\begin{tabular}{lcccc}
\hline Samples & \multicolumn{3}{l}{003} & 006 \\
\hline & $2 \theta$ & d-spacing & $2 \theta$ & d-spacing \\
\hline NiMn-LDHs: powder & 12.00 & 7.37 & 24.25 & 3.66 \\
\hline NiMn-LDHs: after 20 cycle CV & 12.21 & 7.24 & 24.71 & 3.60 \\
\hline NiMn-LDHs (Br-): OCV & 11.95 & 7.40 & 24.46 & 3.63 \\
\hline NiMn-LDHs (Br-): after 2 cycle CV & 11.71 & 7.55 & 24.22 & 3.67 \\
\hline NiMn-LDHs (Br-): after 20 cycle CV & 11.70 & 7.56 & 24.20 & 3.67 \\
\hline
\end{tabular}



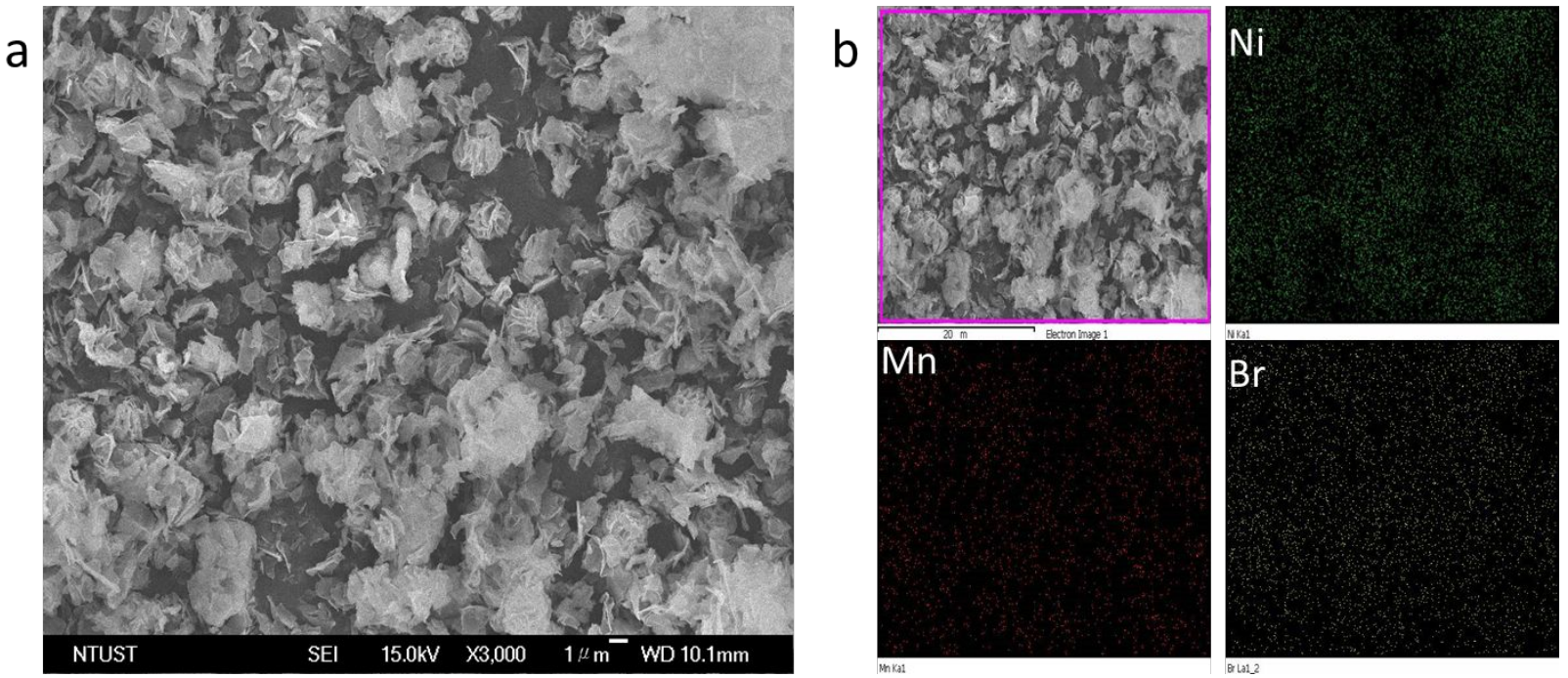

Figure S13. (a) The SEM image of NiMn-LDHs with guest anion (Br-) after OCV and (b) the corresponding elemental distribution maps of $\mathrm{Ni}, \mathrm{Mn}$, and $\mathrm{Br}$ in the NiMn-LDHs electrode.
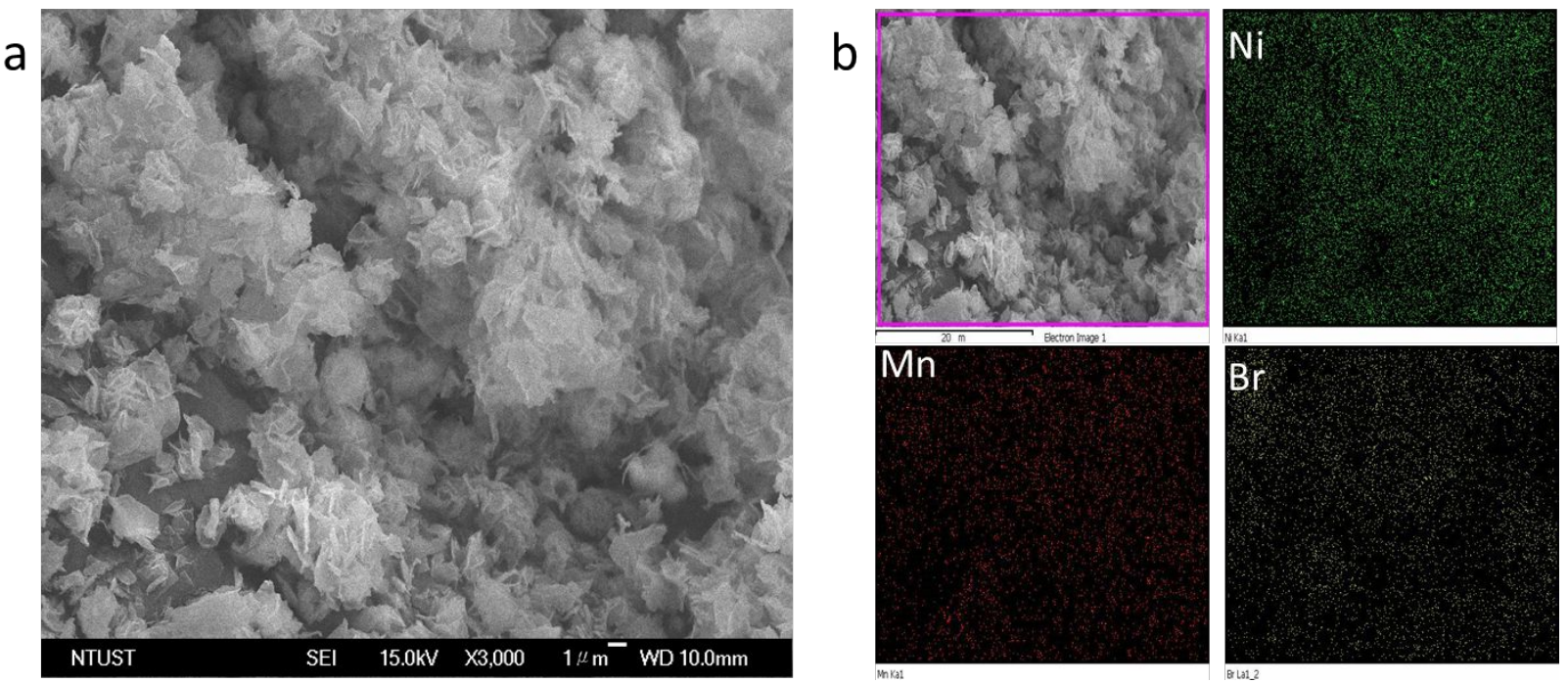

Figure S14. (a) The SEM image of NiMn-LDHs with guest anion (Br-) after 2 cycled $\mathrm{CV}$ measurement and (b) the corresponding elemental distribution maps of $\mathrm{Ni}, \mathrm{Mn}$, and $\mathrm{Br}$ in the NiMn-LDHs electrode. 

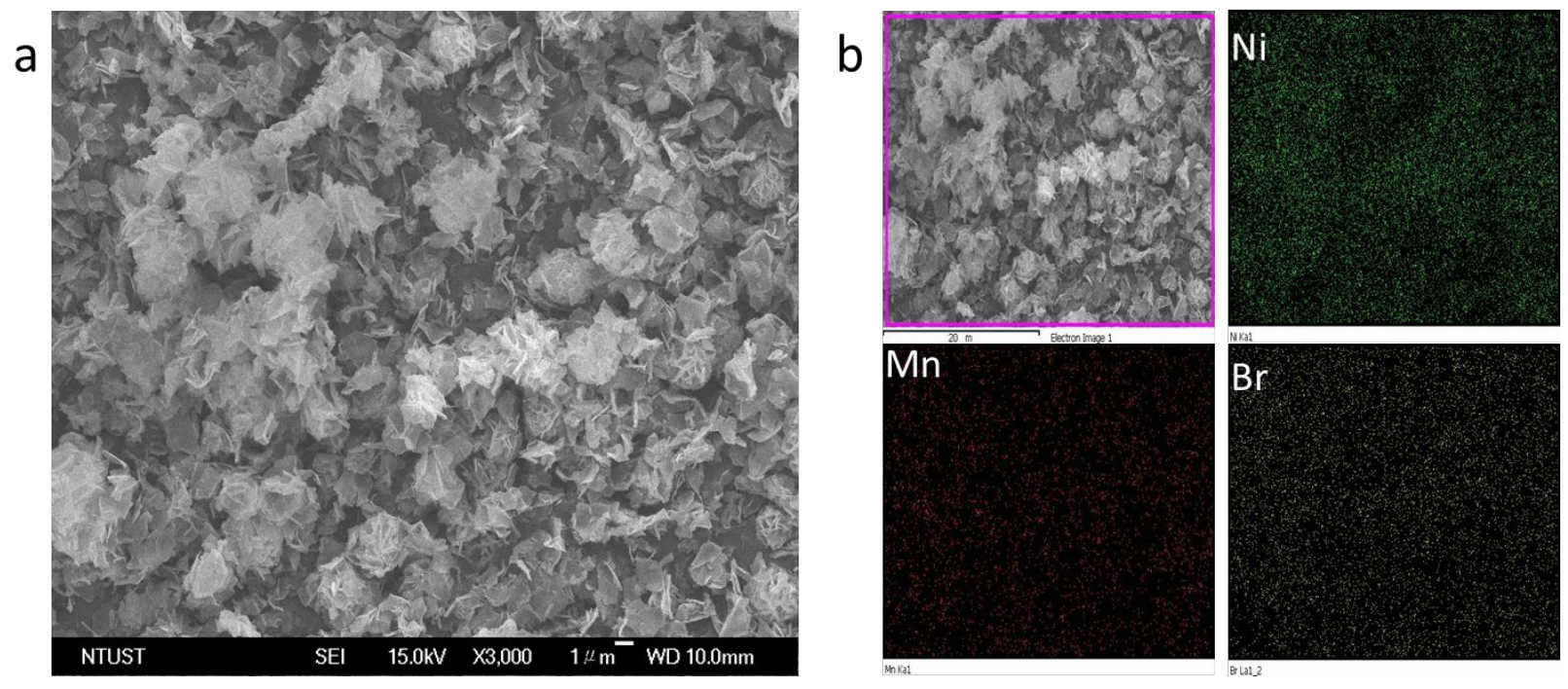

Figure S15. (a) The SEM image of NiMn-LDHs with guest anion $\left(\mathrm{Br}^{-}\right)$after 20 cycled CV measurements and (b) the corresponding elemental distribution maps of $\mathrm{Ni}, \mathrm{Mn}$, and $\mathrm{Br}$ in the NiMn-LDHs electrode. 

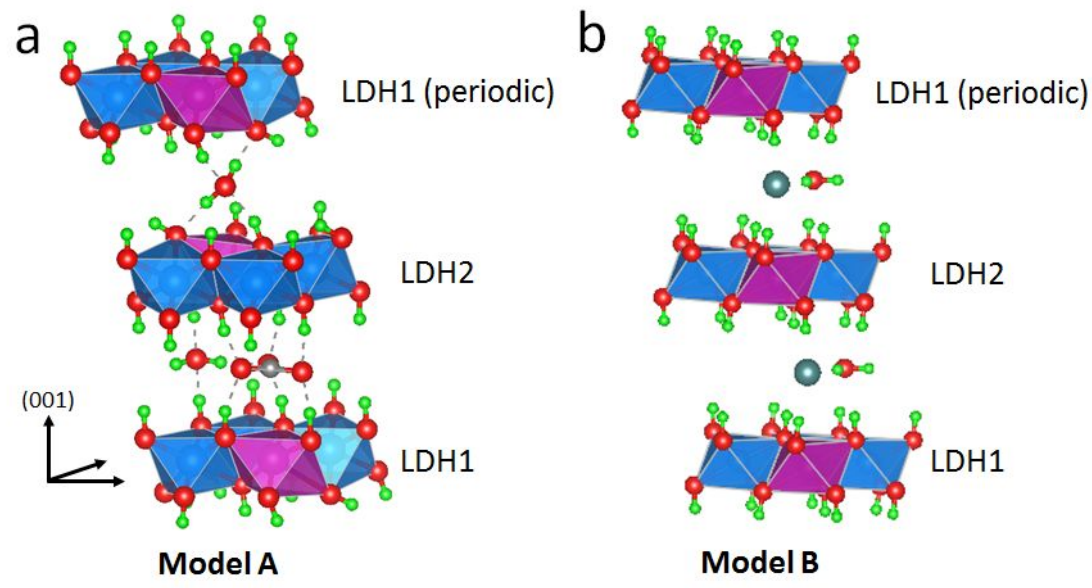

Model B
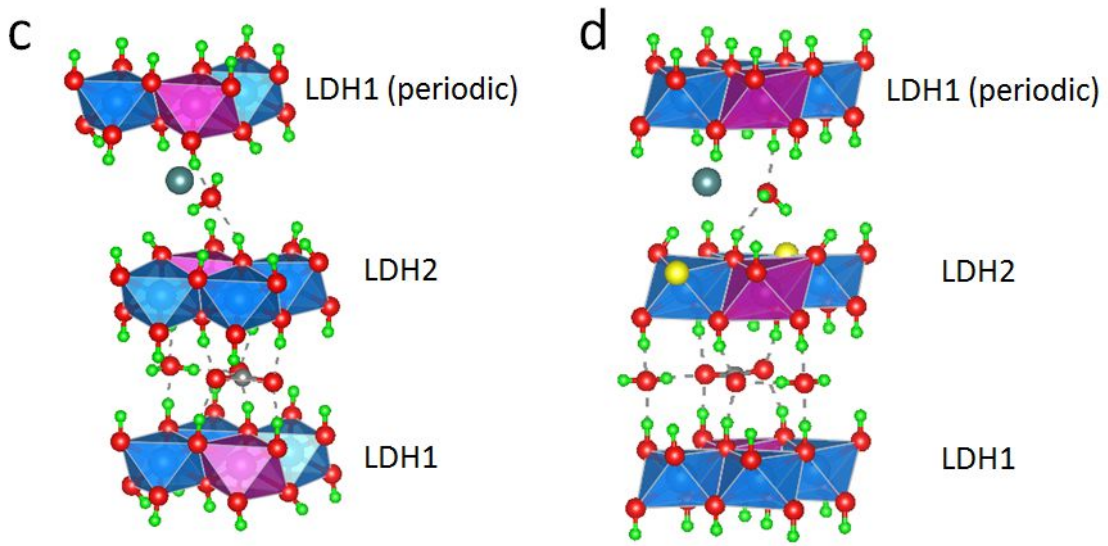

Model C

Model D

Figure S16. (a) A relaxed bulk model of NiMn-LDHs with intercalated $\mathrm{CO}_{3}$ based on a $2 \times 2 \times 2$ supercell of $\mathrm{Ni}(\mathrm{OH})_{2}$ structure, denoted Model A. (b) A relaxed bulk model of two-layers NiMnLDHs with two intercalated Br, denoted Model B. (c) A relaxed bulk model of NiMn-LDHs with a guest anion $\mathrm{Br}$, where $\mathrm{Br}$ ion is located in the space between LDH2 and LDH1 (periodic), denoted Model C (d) A relaxed bulk model of NiMn-LDHs with one NiOOH site (yellow) and guest anion $\mathrm{Br}$, created by removed one hydrogen on $\mathrm{Ni}(\mathrm{OH})_{2}$ site, denoted Model D. Blue, purple, grey, red and green balls represent $\mathrm{Ni}, \mathrm{Mn}$, carbon, oxygen, and hydrogen, respectively. 


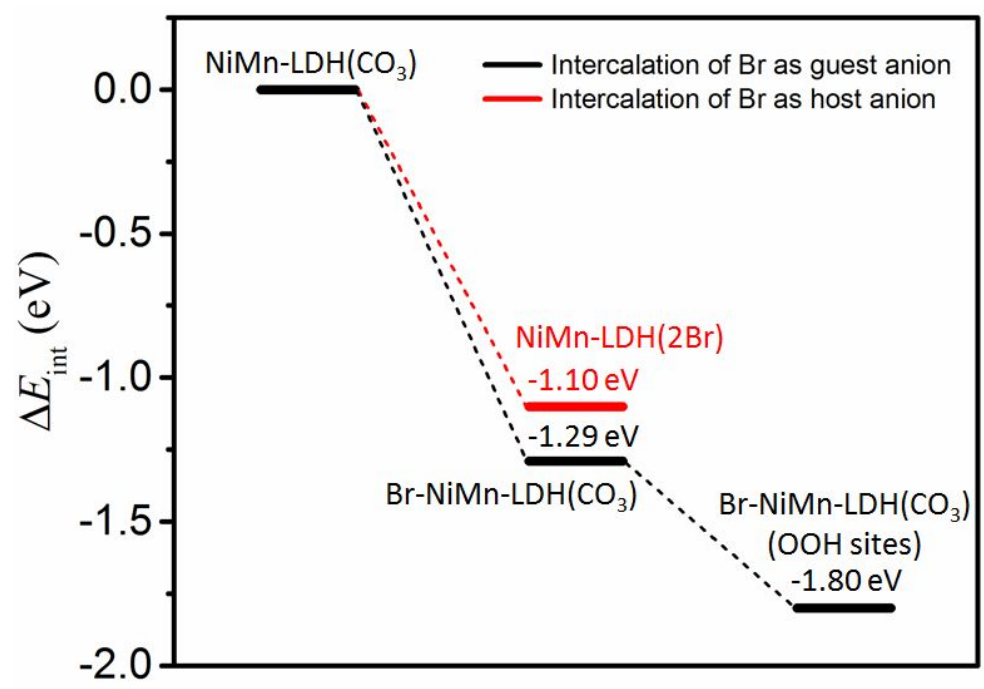

Figure S17. Energy profile of $\Delta E_{\text {int }}$ for $\mathrm{Br}$ as host anion (red) and guest anion (black) in NiMnLDH. The calculations of $\Delta E_{\text {int }}$ are based on the total energy of NiMn- $\mathrm{LDH}\left(\mathrm{CO}_{3}{ }^{2-}\right)$.

Table S4. The calculated intercalation energy of intercalated $\mathrm{CO}_{3}{ }^{2-}$ and $\mathrm{Br}^{-}$anions in the NiMnLDHs and $d$-spacing along the (001) direction in the NiMn-LDHs with different intercalated anions by DFT-D3 calculations.

\begin{tabular}{cccc}
\hline \multirow{2}{*}{ Materials } & Intercalated anion & $\Delta E_{\mathrm{int}} / \mathrm{eV}$ & $\mathrm{d}$-spacing $/ \AA$ \\
\hline \multirow{2}{*}{ NiMn-LDHs } & Host anion $\mathrm{CO}_{3}^{2-}($ Model A) & $\mathrm{N} / \mathrm{A}$ & 6.9 \\
\cline { 2 - 4 } & Host anion $\mathrm{Br}^{-}($Model B) & -1.10 & 7.8 \\
\cline { 2 - 4 } & Guest anion $\mathrm{Br}^{-}($Model C) & -1.29 & 7.3 \\
\cline { 2 - 4 } & Guest anion $\mathrm{Br}^{-}($Model D) & -1.80 & 7.1 \\
\hline
\end{tabular}



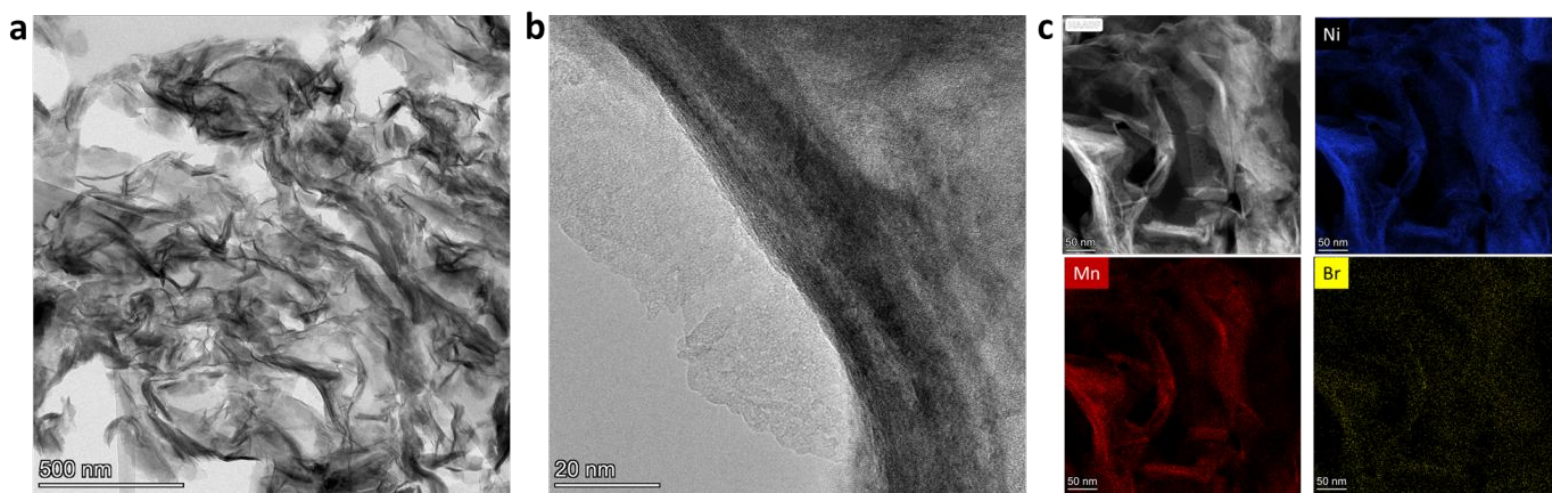

Figure S18. Characterization after the OER stability test. (a) TEM and (b) HRTEM (c) HAADFSTEM images of NiMn-LDHs with guest anions after the OER stability test at a constant overpotential of $270 \mathrm{mV}$ in $1 \mathrm{M} \mathrm{KOH}$ solution $12 \mathrm{~h}$ and the corresponding EDS mapping.

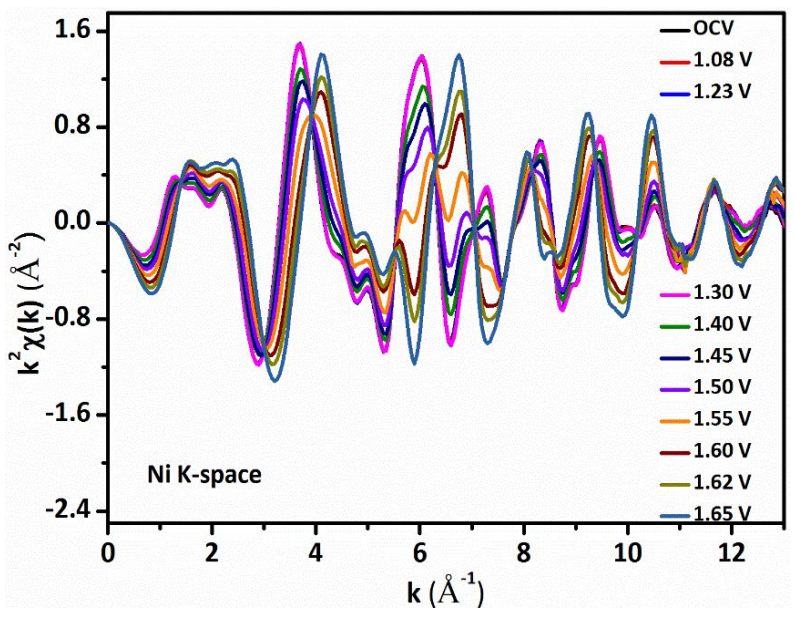

Figure S19. The operando XANES spectra of extended oscillation functions $\mathrm{k}^{2} \chi(\mathrm{k})$ for Ni K-edge of NiMn-LDHs catalyst. 

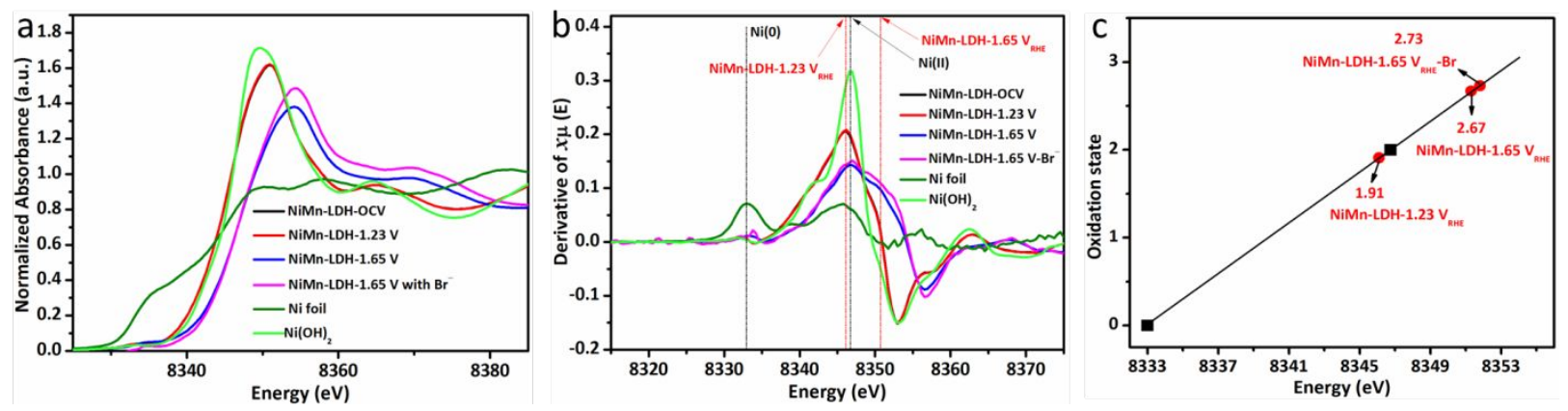

Figure S20. (a) Normalized XANES spectra of Ni K-edge, (b) the first derivative of the normalized XANES spectra of Ni K-edge, and (c) the average oxidation state of Ni ion in NiMnLDHs obtained from the XANES spectra during the OER process. The in situ XANES spectra evidencing that the valence state of $\mathrm{Ni}$ ion is less than +3 during the OER process even under high overpotential $(1.65 \mathrm{~V})$. 
Table S5. Local structure parameters of $\mathrm{Ni}^{2+}$ and in situ generated $\mathrm{Ni}^{3+}$ sites estimated by EXAFS analysis for NiMn-LDHs

\begin{tabular}{|c|c|c|c|c|c|c|c|c|c|c|c|}
\hline \multirow[b]{2}{*}{$\mathrm{E}_{\text {applied }}$} & \multicolumn{3}{|c|}{$\mathrm{Ni}^{2+}$ phase } & \multicolumn{4}{|c|}{$\mathrm{Ni}^{3+}$ phase } & \multicolumn{4}{|c|}{ Summary } \\
\hline & $N_{\mathrm{Ni}-\mathrm{O}}$ & $d_{\mathrm{Ni}-\mathrm{O}}$ & $N_{\mathrm{Ni}-\mathrm{M}}$ & $d_{\mathrm{Ni}-\mathrm{M}}$ & $N_{\mathrm{Ni}-\mathrm{O}}$ & $d_{\mathrm{Ni}-\mathrm{O}}$ & $N_{\mathrm{Ni}-\mathrm{M}}$ & $d_{\mathrm{Ni}-\mathrm{M}}$ & R- & Total & Total \\
\hline & & & & & & & & & factor & $N_{\mathrm{Ni}-\mathrm{O}}$ & $N_{\mathrm{Ni}-\mathrm{M}}$ \\
\hline 1.08 & $4.82 \pm 0.43$ & $2.03 \pm 0.01$ & $6.00 \pm 0.33$ & $3.11 \pm 0.01$ & $\mathrm{n} / \mathrm{a}$ & $\mathrm{n} / \mathrm{a}$ & $\mathrm{n} / \mathrm{a}$ & $\mathrm{n} / \mathrm{a}$ & 0.0014 & 4.82 & 6.00 \\
\hline 1.23 & $4.94 \pm 0.43$ & $2.03 \pm 0.01$ & $6.00 \pm 0.32$ & $3.11 \pm 0.01$ & $\mathrm{n} / \mathrm{a}$ & $\mathrm{n} / \mathrm{a}$ & $\mathrm{n} / \mathrm{a}$ & $\mathrm{n} / \mathrm{a}$ & 0.0013 & 4.94 & 6.00 \\
\hline 1.30 & $4.93 \pm 0.45$ & $2.03 \pm 0.01$ & $6.00 \pm 0.32$ & $3.11 \pm 0.01$ & $\mathrm{n} / \mathrm{a}$ & $\mathrm{n} / \mathrm{a}$ & $\mathrm{n} / \mathrm{a}$ & $\mathrm{n} / \mathrm{a}$ & 0.0013 & 4.93 & 6.00 \\
\hline 1.40 & $4.63 \pm 0.56$ & $2.03 \pm 0.01$ & $5.08 \pm 0.29$ & $3.10 \pm 0.01$ & $\mathrm{n} / \mathrm{a}$ & $\mathrm{n} / \mathrm{a}$ & $0.92 \pm 0.05$ & $2.86 \pm 0.03$ & 0.0008 & 4.63 & 6.00 \\
\hline 1.45 & $3.31 \pm 0.47$ & $2.04 \pm 0.11$ & $4.71 \pm 0.37$ & $3.10 \pm 0.02$ & $1.33 \pm 0.37$ & $1.92 \pm 0.14$ & $1.29 \pm 0.01$ & $2.85 \pm 0.03$ & 0.0027 & 4.64 & 6.00 \\
\hline 1.50 & $2.50 \pm 0.91$ & $2.05 \pm 0.04$ & $4.18 \pm 0.22$ & $3.10 \pm 0.02$ & $1.67 \pm 0.64$ & $1.91 \pm 0.05$ & $1.82 \pm 0.09$ & $2.84 \pm 0.02$ & 0.0032 & 4.18 & 6.00 \\
\hline 1.55 & $1.90 \pm 0.56$ & $2.07 \pm 0.06$ & $3.29 \pm 0.18$ & $3.10 \pm 0.02$ & $2.38 \pm 1.15$ & $1.91 \pm 0.05$ & $2.71 \pm 0.15$ & $2.84 \pm 0.02$ & 0.0044 & 4.28 & 6.00 \\
\hline 1.60 & $1.05 \pm 0.42$ & $2.07 \pm 0.07$ & $2.23 \pm 0.13$ & $3.11 \pm 0.01$ & $2.97 \pm 0.86$ & $1.90 \pm 0.02$ & $3.77 \pm 0.22$ & $2.84 \pm 0.01$ & 0.0017 & 4.02 & 6.00 \\
\hline 1.62 & $0.76 \pm 0.55$ & $2.03 \pm 0.09$ & $1.90 \pm 0.11$ & $3.10 \pm 0.01$ & $2.97 \pm 1.04$ & $1.88 \pm 0.03$ & $4.10 \pm 0.25$ & $2.85 \pm 0.01$ & 0.0009 & 3.73 & 6.00 \\
\hline 1.63 & $0.34 \pm 0.35$ & $2.05 \pm 0.12$ & $1.40 \pm 1.40$ & $3.09 \pm 0.01$ & $3.59 \pm 0.61$ & $1.88 \pm 0.01$ & $4.60 \pm 0.26$ & $2.85 \pm 0.01$ & 0.0002 & 3.93 & 6.00 \\
\hline
\end{tabular}
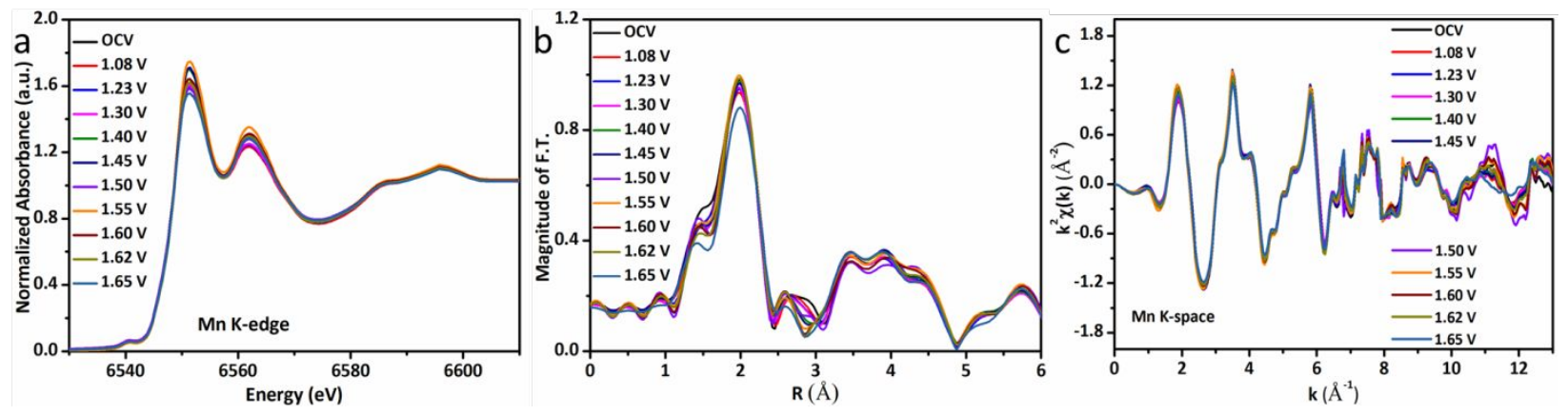

Figure S21. (a) In situ XANES spectra (b) Magnitude of in situ FT-EXAFS spectra of Mn K-edge for NiMn-LDHs electrocatalyst under the same conditions. (c) In situ XANES spectra of extended oscillation functions $\mathrm{k}^{2} \chi(\mathrm{k})$ for Mn K-edge of NiMn-LDHs catalyst. 

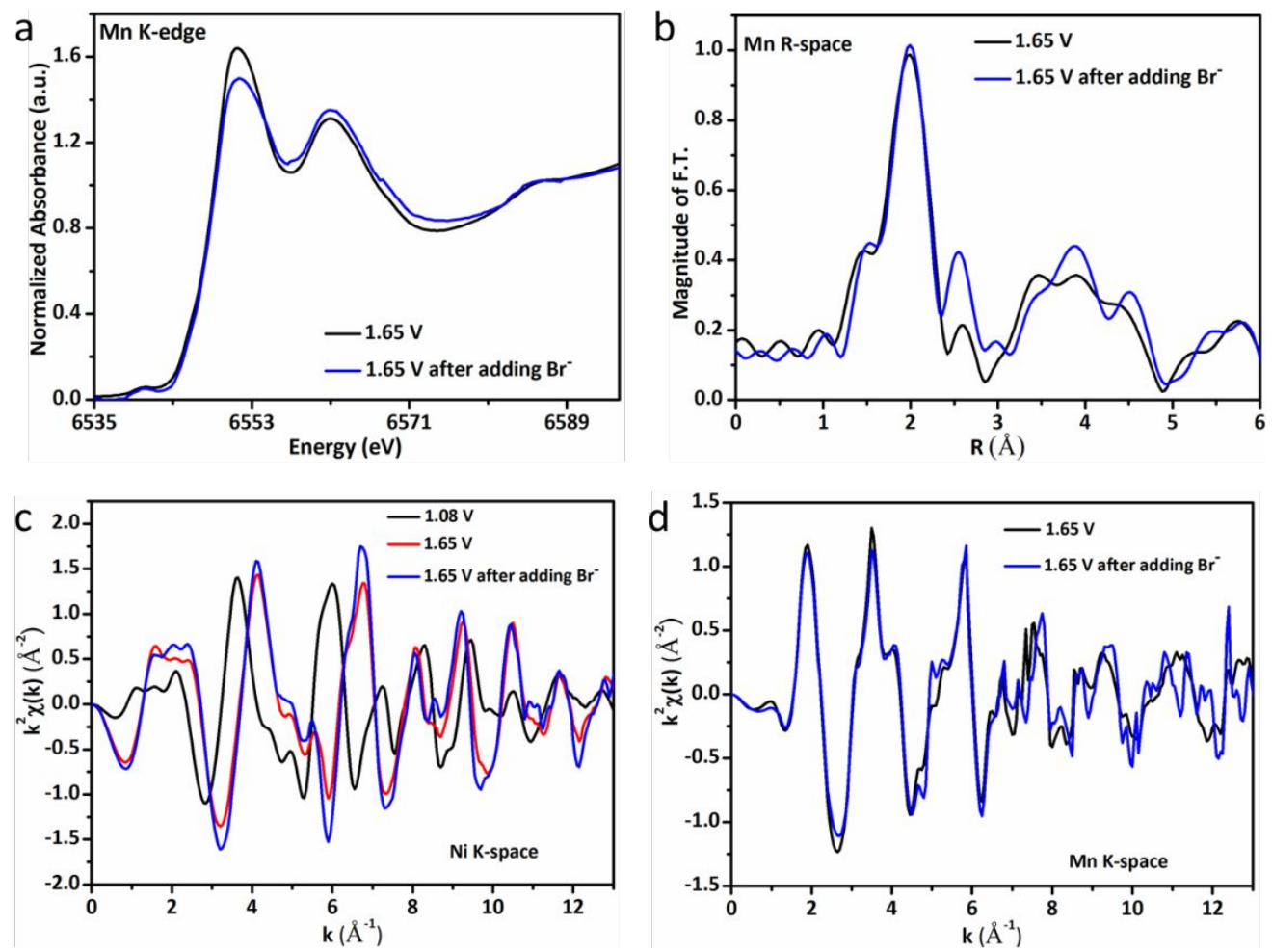

Figure S22. (a) In situ XANES (b) Magnitude of FT-EXAFS spectra of Mn K-edge and (c, d) Extended XANES oscillation functions $\mathrm{k}^{2} \chi(\mathrm{k})$ of Ni K-edge and Mn K-edge for NiMn-LDHs before and after bromide guest anion introduced into the electrolyte during the OER.

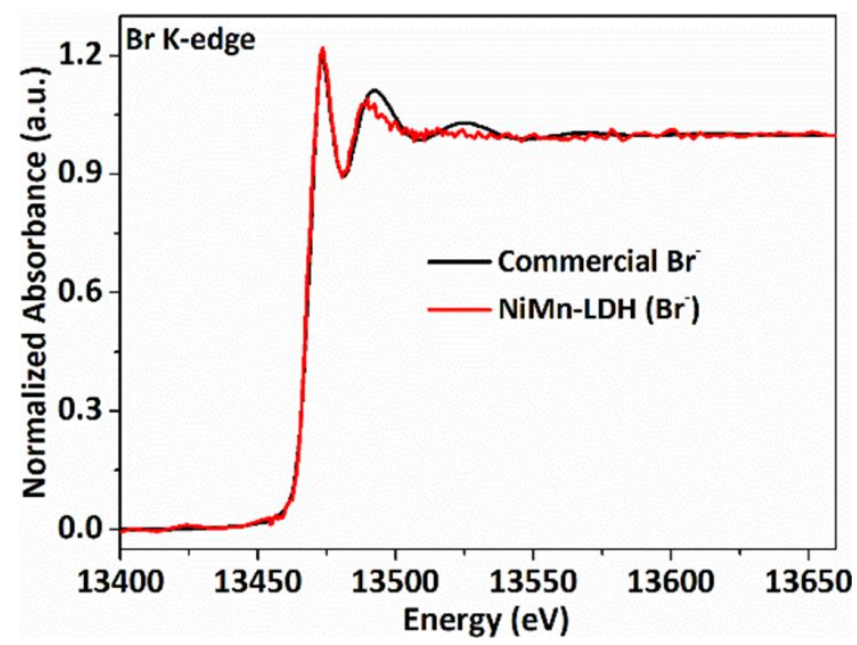

Figure S23. Normalized XANES spectra of Br K-edge for commercial bromide sample and NiMnLDHs $\left(\mathrm{Br}^{-}\right)$electrode after the OER stability test. 
To probe the active site, oxidation state and structural changes of NiMn-LDHs and $\beta-\mathrm{Ni}(\mathrm{OH})_{2}$ catalysts during the OER, we carried out in situ Raman measurements under the same electrochemical conditions (Figures S24-27). During the measurements, the working electrode potential was increased in steps from the open-circuit voltage (OCV $\sim 1.65 \mathrm{~V} v s$. RHE). Each potential was held for at least 15 min until the spectra were recorded. The study of the structural change during the catalytic activity of NiMn-LDHs and $\beta-\mathrm{Ni}(\mathrm{OH})_{2}$ catalysts and the effect of guest anion lets us know the active sites and better understanding of the site activity and accessible site populations associated with the overall activity.
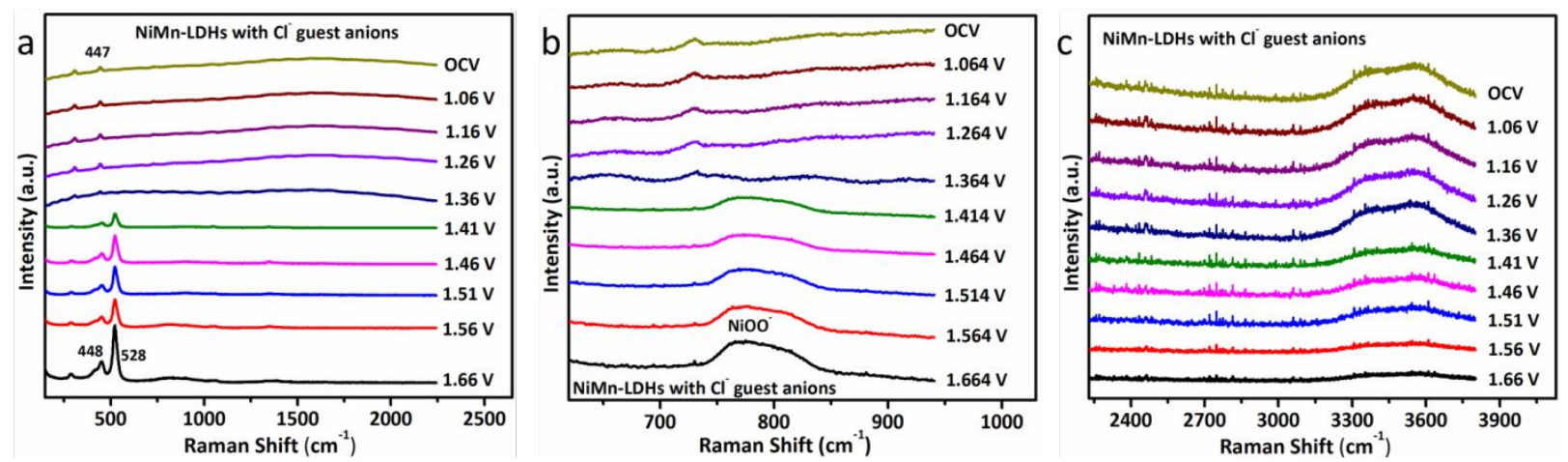

Figure S24. The in situ Raman spectra of NiMn-LDHs collected during the OER in the presence of guest anion (13 mM of chloride) in the potential window of 1.064-1.664 V vs. RHE in $0.1 \mathrm{M}$ $\mathrm{KOH}$.

The in situ Raman spectra of NiMn-LDHs (Figure S25a) before a redox transition from 1.064 to $1.364 \mathrm{~V}$ display a single peak at $458 \mathrm{~cm}^{-1}$, which is assigned to the stretching modes of $\mathrm{Ni}-\mathrm{O}$ of $\mathrm{Ni}(\mathrm{OH})_{2}$ species of LDHs. ${ }^{18}$ The redox transition of $\mathrm{Ni}(\mathrm{OH})_{2} / \mathrm{NiOOH}$ of NiMn-LDHs occurs at the potentials higher than $1.364 \mathrm{~V}$ (i.e., at the anodic wave seen in CV) and the two peaks at 450 and $530 \mathrm{~cm}^{-1}$ in the Raman spectra at a potentials higher than $1.364 \mathrm{~V}$ attributed to the $e_{\mathrm{g}}$ bending and $\mathrm{A}_{\mathrm{lg}}$ stretching modes of $\mathrm{Ni}-\mathrm{O}$ in $\mathrm{NiOOH}$, respectively, which is consistent with the previously 
reported literature for NiFe-LDHs. ${ }^{19}, 20$ The in situ Raman spectra of NiMn-LDHs were also collected at high Raman shifts $\left(2500-3800 \mathrm{~cm}^{-1}\right)$ to see the vibrational stretching modes of $\mathrm{O}-\mathrm{H}$ during the OER process (Figure S25b). The broad band at about $3581 \mathrm{~cm}^{-1}$ is assigned to $\mathrm{O}-\mathrm{H}$ vibrations of disordered $\mathrm{Ni}(\mathrm{OH})_{2}$ in NiMn-LDHs. This feature further reveals that introduction of Mn into ordered $\beta-\mathrm{Ni}(\mathrm{OH})_{2}$ results in structurally disordered LDHs which is beneficial for the enhanced OER activity. This band rapidly weakens and is absent as the electrode potential turns above $1.464 \mathrm{~V}$ (i.e., the OER potential range), suggesting that deprotonated $\mathrm{NiOOH}$ species. In the case of in situ Raman spectra of $\beta-\mathrm{Ni}(\mathrm{OH})_{2}$, Figure S27a, the band at $458 \mathrm{~cm}^{-1}$ below $1.364 \mathrm{~V}$ is attributed to the stretching modes of $\mathrm{Ni}-\mathrm{O}$ in $\mathrm{Ni}(\mathrm{OH})_{2} \cdot{ }^{21}$ The pair of peaks observed at 479 and $528 \mathrm{~cm}^{-1}$ above the potential of $1.464 \mathrm{~V}$ attributed to the bending vibration and stretching modes of $\mathrm{Ni}-\mathrm{O}$ in $\mathrm{NiOOH}$ resulted from the redox transition of $\mathrm{Ni}(\mathrm{OH})_{2} / \mathrm{NiOOH}{ }^{18,21}$ The Raman features at $3580 \mathrm{~cm}^{-1}$ ascribed to $\mathrm{O}-\mathrm{H}$ vibrations of $\mathrm{Ni}(\mathrm{OH})_{2}($ Figure $\mathbf{S 2 7 b})$ and this peak is absent in the OER potential range above $1.514 \mathrm{~V}$, suggesting deprotonated $\mathrm{NiOOH}$ species.
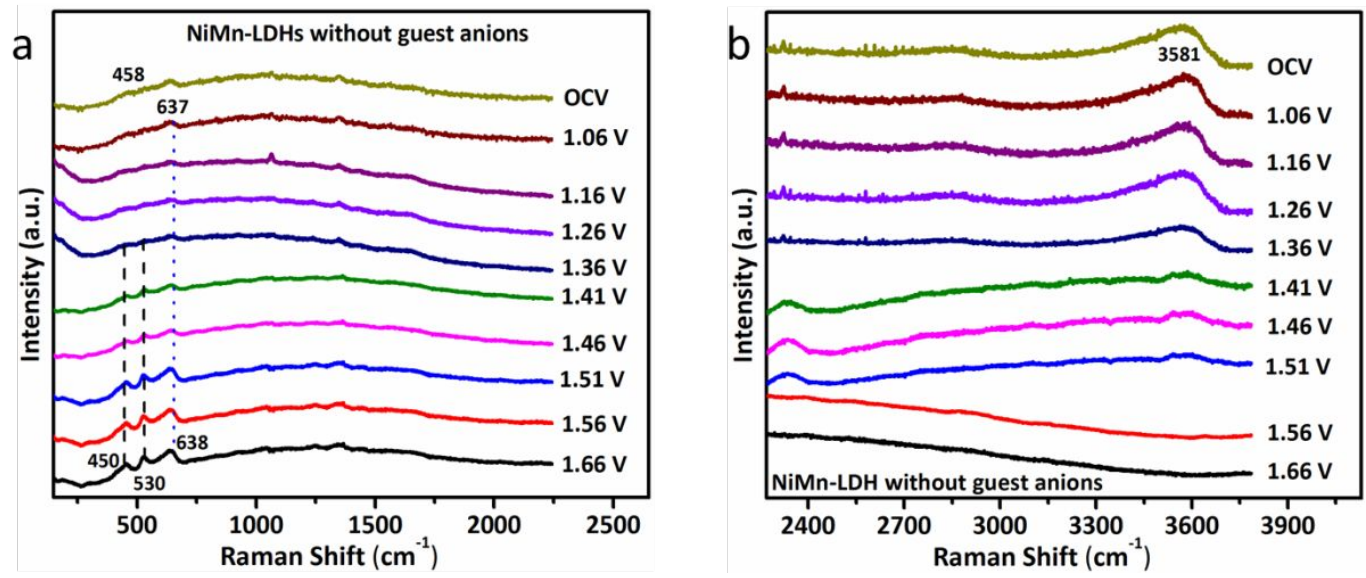

Figure S25. Operando Raman spectra of NiMn-LDHs attained in the potential window of 1.064-1.664 V vs. RHE in $0.1 \mathrm{M} \mathrm{KOH}$ electrolyte. The measurements were conducted chronoamperometrically. 

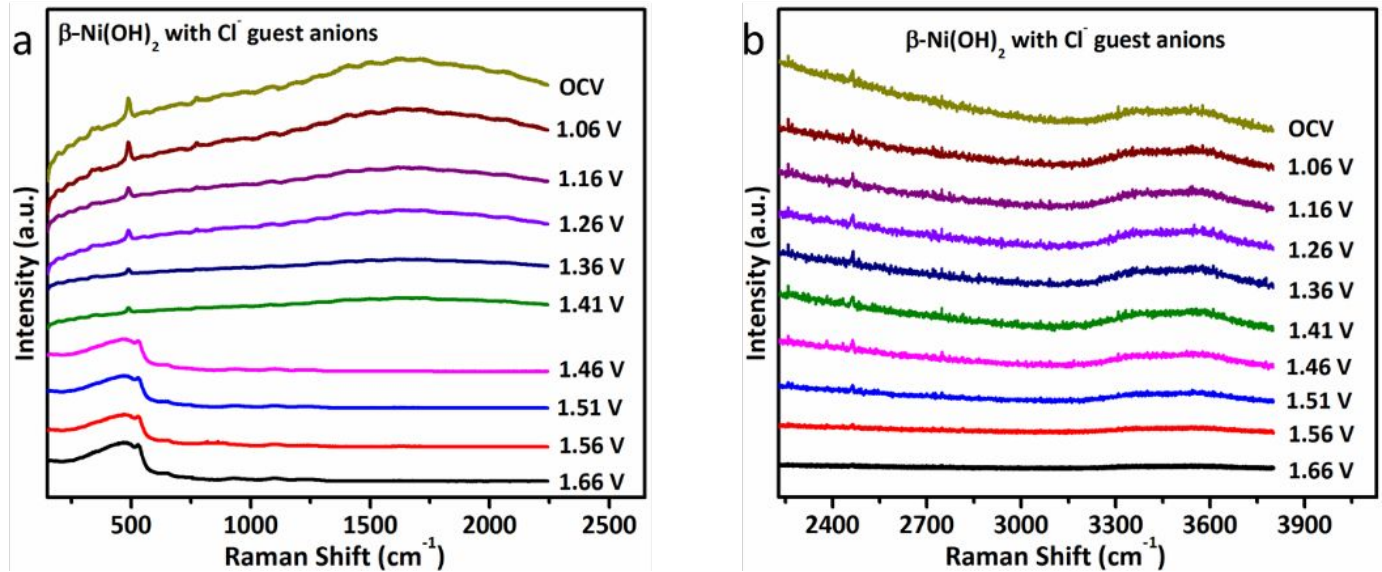

Figure S26. Operando Raman spectra of $\beta-\mathrm{Ni}(\mathrm{OH})_{2}$ collected during the OER in the presence of guest anion (13 $\mathrm{mM}$ of chloride) in $0.1 \mathrm{M} \mathrm{KOH}$.

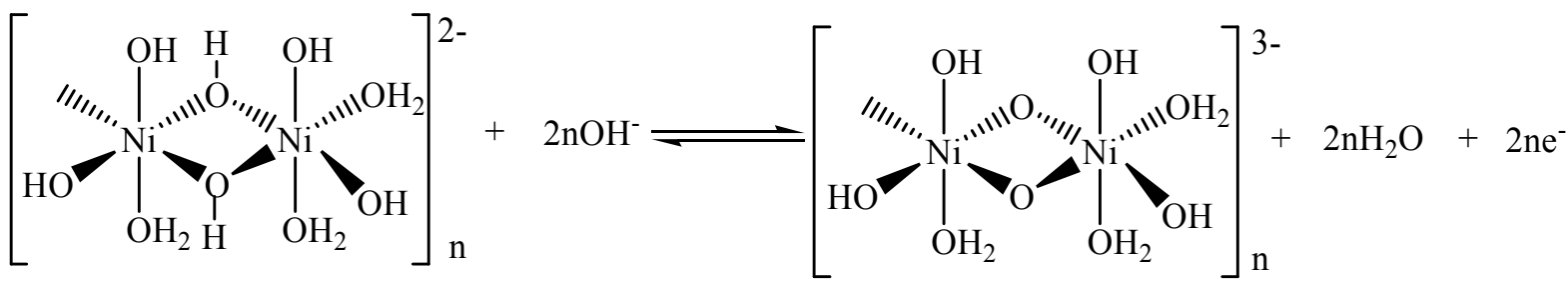

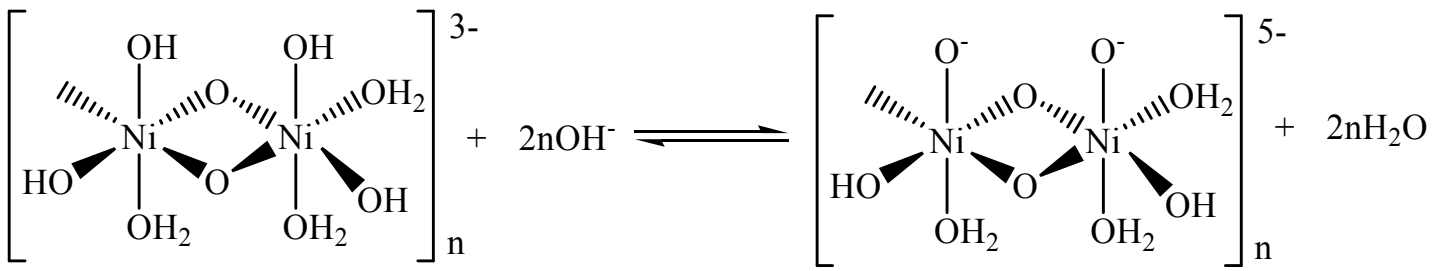

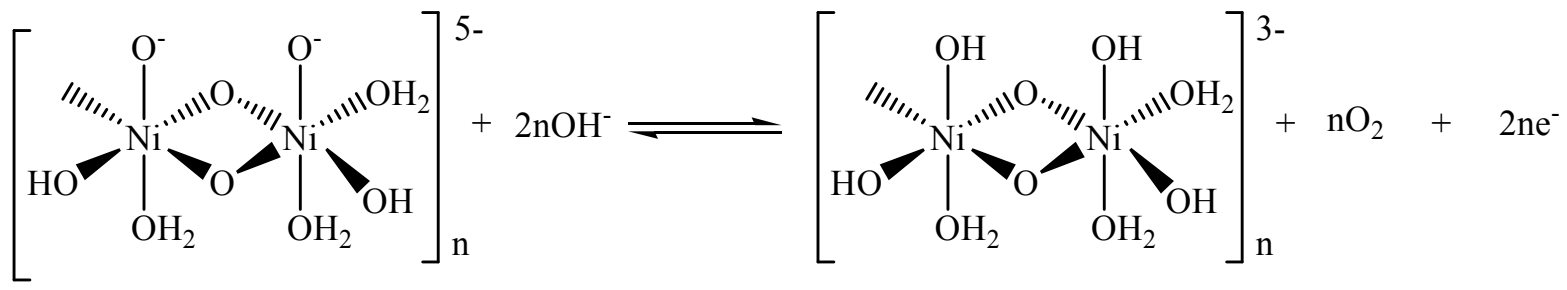

Scheme S1. The hypothesized OER mechanism on NiMn-LDHs catalyst was suggested by the operando XAS and operando Raman measurements. 

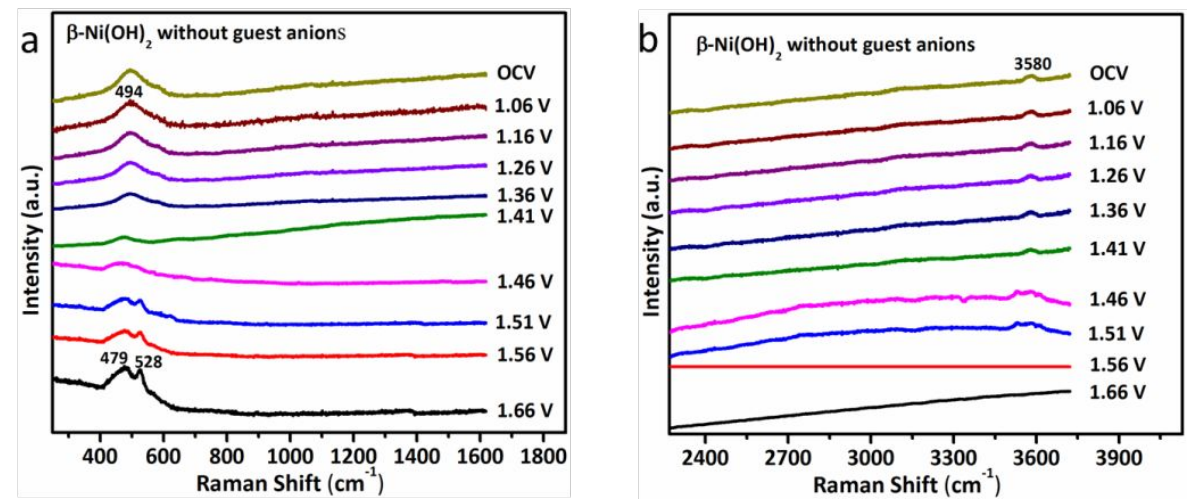

Figure S27. Operando Raman spectra of synthesized ordered $\beta-\mathrm{Ni}(\mathrm{OH})_{2}$ attained in the potential window of 1.064-1.664 V vs. RHE in $0.1 \mathrm{M} \mathrm{KOH}$ electrolyte.

a
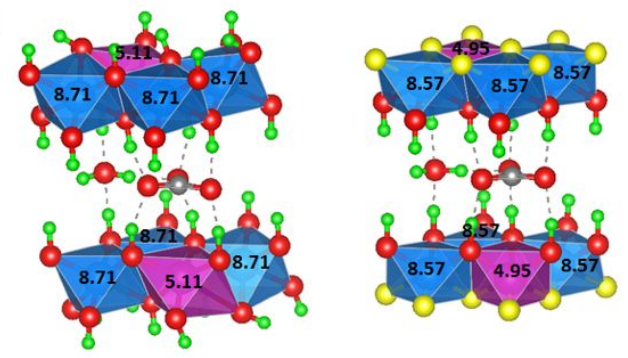

b
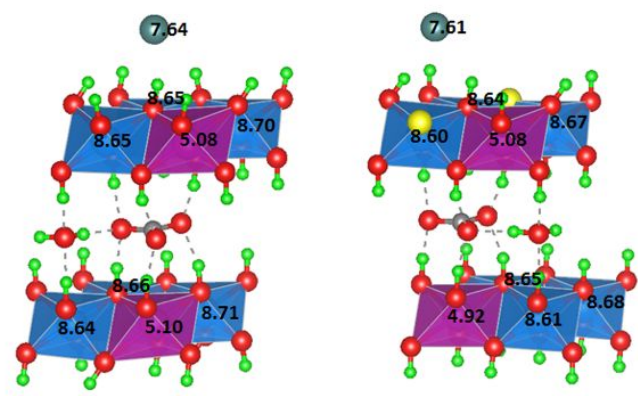

Figure S28. Bader charge analysis for $\mathrm{NiMn}-\mathrm{LDH}\left(\mathrm{CO}_{3}\right)$ without/with intercalation of guest anion Br. The values nearby different atoms represent Bader charge. (a) NiMn-LDH( $\left.\mathrm{CO}_{3}\right)$, left: $\mathrm{Ni}(\mathrm{OH})_{2}$ structure, and right: $\mathrm{NiOOH}$ structure. (b) NiMn- $\mathrm{LDH}\left(\mathrm{CO}_{3}\right)$ with intercalation of guest anion $\mathrm{Br}$, left: $\mathrm{Ni}(\mathrm{OH})_{2}$ structure and right: one $\mathrm{NiOOH}$ site (yellow ball). Blue, purple, grey, red, green, and cyan balls represent $\mathrm{Ni}, \mathrm{Mn}$, carbon, oxygen, hydrogen, and $\mathrm{Br}$, respectively. 
To verify the interaction between the two metals after hybridization, the partial electron transfer process from $\mathrm{Ni}$ to $\mathrm{Mn}$ through the oxygen ligand is explained in terms of their electronic configuration as shown in Figure S29. The valence state of $\mathrm{Ni}^{2+}$ electronic configuration is $3 \mathrm{~d}^{8}$ and exhibits the high spin state of octahedral geometry. Thus, the $t_{2} g$ ( $\pi$-symmetry d-orbitals) of $3 \mathrm{~d}^{8}$ octahedral geometry of $\mathrm{Ni}^{2+}$ is fully occupied. As such, the major electronic interaction between the bridging and $\mathrm{Ni}^{2+}$ is $\mathrm{e}^{-}-\mathrm{e}^{-}$repulsion. Similarly, the valence state of $\mathrm{Mn}^{3+}$ electronic configuration is $3 \mathrm{~d}^{4}$ and exhibits high spin octahedral geometry with an unpaired electron in the $\pi$-symmetry of $\mathrm{t}_{2} \mathrm{~g}$ orbitals. Hence, $\mathrm{Mn}^{3+}$ interacts with the bridging $\mathrm{O}^{2-}$ via $\pi$-donation. We, therefore, claim that the $\pi$-donation of $\mathrm{Mn}-\mathrm{O}$ can be intensified by the $\mathrm{e}^{-}-\mathrm{e}^{-}$repulsion between $\mathrm{Ni}^{2+}$ and $\mathrm{O}^{2-}$, which generates the partial charge transfer between $\mathrm{Mn}$ and $\mathrm{Ni}$. This can indicate that the coupling between the $\mathrm{Ni}$ and $\mathrm{Mn}$ could induce a change in electronic and conductivity properties which in turn improves the OER activity. The spectro-electrochemical experiments have further verified the advantage of the coupling effect between $\mathrm{Ni}$ and $\mathrm{Mn}$, which accounts for the improved OER activity of NiMn-LDHs compared with $\beta-\mathrm{Ni}(\mathrm{OH})_{2}$.

Oxidation state \& electronic state:
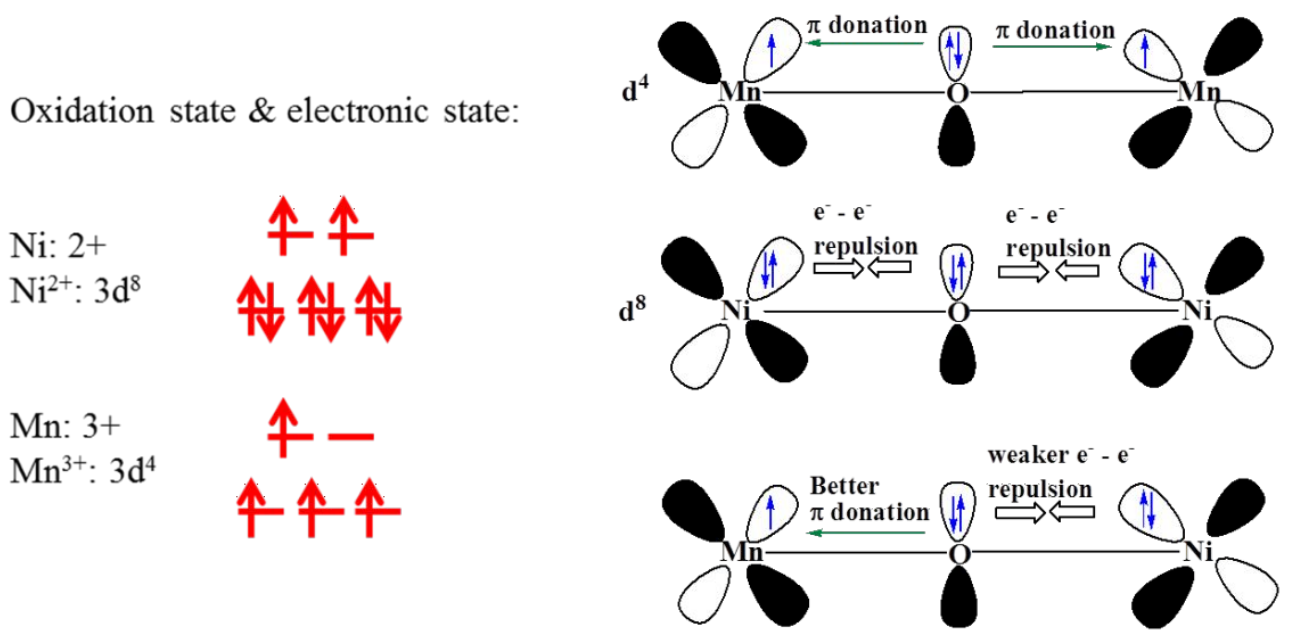

Figure S29. The schematic representation of the electronic coupling between $\mathrm{Ni}$ and $\mathrm{Mn}$ species in NiMn-LDHs. 


\section{References}

1. Hwang, B. J.; Senthil Kumar, S. M.; Chen, C.-H.; Chang, R.-W.; Liu, D.-G.; Lee, J.-F., Size and Alloying Extent Dependent Physiochemical Properties of Pt-Ag/C Nanoparticles Synthesized by the Ethylene Glycol Method. J. Phys. Chem. C 2008, 112, 2370-2377.

2. Kresse, G.; Hafner, J., Ab Initio Molecular Dynamics for Liquid Metals. Phys. Rev. B 1993, 47, 558561.

3. Perdew, J.; Burke, K.; Ernzerhof, M., of Physics, D.; Quantum Theory Group Tulane University, NOL 70118. J. Phys. Rev. Lett. 1996, 77, 3865-3868.

4. Kresse, G.; Joubert, D., From Ultrasoft Pseudopotentials to the Projector Augmented-Wave Method. Phys. Rev. B 1999, 59, 1758.

5. Grimme, S.; Antony, J.; Ehrlich, S.; Krieg, H., A Consistent and Accurate $a b$ Initio Parametrization of Density Functional Dispersion Correction (DFT-D) for the 94 Elements H-Pu. J. Chem. Phys. 2010, 132, 154104.

6. Grimme, S.; Ehrlich, S.; Goerigk, L., Effect of the Damping Function in Dispersion Corrected Density Functional Theory. J. Comput. Chem. 2011, 32, 1456-1465.

7. Chala, S. A.; Tsai, M.-C.; Su, W.-N.; Ibrahim, K. B.; Duma, A. D.; Yeh, M.-H.; Wen, C.-Y.; Yu, C.-H.; Chan, T.-S.; Dai, H.; Hwang, B.-J., Site Activity and Population Engineering of NiRu-Layered Double Hydroxide Nanosheets Decorated with Silver Nanoparticles for Oxygen Evolution and Reduction Reactions. ACS Catal. 2019, 9, 117-129.

8. $\quad$ Gong, M.; Li, Y.; Wang, H.; Liang, Y.; Wu, J. Z.; Zhou, J.; Wang, J.; Regier, T.; Wei, F.; Dai, H., An Advanced Ni-Fe Layered Double Hydroxide Electrocatalyst for Water Oxidation. J. Am. Chem. Soc. 2013, $135,8452-8455$.

9. $\quad$ Chala, S. A.; Tsai, M.-C.; Su, W.-N.; Dai, H.; Hwang, B. J., Layered Double Hydroxide Nanosheets Decorated with Metal or Metal Oxides for Oxygen Evolution and Reduction Reactions, Abstracts of Papers of the American Chemical Society, Am. Chem. Soc. 1155 16th St, NW, Washington, DC 20036 USA: 2019.

10. Fan, K.; Chen, H.; Ji, Y.; Huang, H.; Claesson, P. M.; Daniel, Q.; Philippe, B.; Rensmo, H.; Li, F.; Luo, Y.; Sun, L., Nickel-Vanadium Monolayer Double Hydroxide for Efficient Electrochemical Water Oxidation. Nat. Commun. 2016, 7, 11981.

11. Chala, S. A.; Tsai, M.-C.; Su, W.-N.; Ibrahim, K. B.; Thirumalraj, B.; Chan, T.-S.; Lee, J.-F.; Dai, H.; Hwang, B.-J., Hierarchical 3D Architectured Ag Nanowires Shelled with NiMn-Layered Double Hydroxide as an Efficient Bifunctional Oxygen Electrocatalyst. ACS Nano 2020, 14, 1770-1782.

12. Zhang, J.; Liu, J.; Xi, L.; Yu, Y.; Chen, N.; Sun, S.; Wang, W.; Lange, K. M.; Zhang, B., Single-Atom $\mathrm{Au} / \mathrm{NiFe}$ Layered Double Hydroxide Electrocatalyst: Probing the Origin of Activity for Oxygen Evolution Reaction. J. Am. Chem. Soc. 2018, 140, 3876-3879.

13. Zhou, D.; Cai, Z.; Lei, X.; Tian, W.; Bi, Y.; Jia, Y.; Han, N.; Gao, T.; Zhang, Q.; Kuang, Y.; Pan, J.; Sun, X.; Duan, X., NiCoFe-Layered Double Hydroxides/N-Doped Graphene Oxide Array Colloid Composite as an Efficient Bifunctional Catalyst for Oxygen Electrocatalytic Reactions. Adv. Energy Mater. 2018, 8, 1701905.

14. Zhao, S.; Wang, Y.; Dong, J.; He, C.-T.; Yin, H.; An, P.; Zhao, K.; Zhang, X.; Gao, C.; Zhang, L.; Lv, J.; Wang, J.; Zhang, J.; Khattak, A. M.; Khan, N. A.; Wei, Z.; Zhang, J.; Liu, S.; Zhao, H.; Tang, Z., Ultrathin Metal-Organic Framework Nanosheets for Electrocatalytic Oxygen Evolution. Nat. Energy 2016, 1, 16184. 
15. Wang, Y.; Zhang, Y.; Liu, Z.; Xie, C.; Feng, S.; Liu, D.; Shao, M.; Wang, S., Layered Double Hydroxide Nanosheets with Multiple Vacancies Obtained by Dry Exfoliation as Highly Efficient Oxygen Evolution Electrocatalysts. Angew. Chem., Int. Ed. 2017, 56, 5867-5871.

16. Liu, R.; Wang, Y.; Liu, D.; Zou, Y.; Wang, S., Water-Plasma-Enabled Exfoliation of Ultrathin Layered Double Hydroxide Nanosheets with Multivacancies for Water Oxidation. Adv. Mater. 2017, 29, 1701546.

17. Li, C.; Zhang, Z.; Liu, R., In Situ Growth of 3D NiFe LDH-POM Micro-Flowers on Nickel Foam for Overall Water Splitting. Small 2020, 16, 2003777.

18. Lo, Y. L.; Hwang, B. J., In Situ Raman Studies on Cathodically Deposited Nickel Hydroxide Films and Electroless Ni-P Electrodes in $1 \mathrm{M} \mathrm{KOH}$ Solution. Langmuir 1998, 14, 944-950.

19. Diaz-Morales, O.; Raaijman, S.; Kortlever, R.; Kooyman, P. J.; Wezendonk, T.; Gascon, J.; Fu, W. T.; Koper, M. T. M., Iridium-Based Double Perovskites for Efficient Water Oxidation in Acid Media. Nat. Commun. 2016, 7, 12363.

20. Yang, L.; Liu, D.; Hao, S.; Kong, R.; Asiri, A. M.; Zhang, C.; Sun, X., A Cobalt-Borate Nanosheet Array: An Efficient and Durable Non-Noble-Metal Electrocatalyst for Water Oxidation at near Neutral pH. J. Mater. Chem. A 2017, 5, 7305-7308.

21. Trześniewski, B. J.; Diaz-Morales, O.; Vermaas, D. A.; Longo, A.; Bras, W.; Koper, M. T. M.; Smith, W. A., In Situ Observation of Active Oxygen Species in Fe-Containing Ni-Based Oxygen Evolution Catalysts: The Effect of pH on Electrochemical Activity. J. Am. Chem. Soc. 2015, 137, 15112-15121. 